\title{
BODY-MASS ESTIMATION IN PALEONTOLOGY: A REVIEW OF VOLUMETRIC TECHNIQUES
}

\author{
Charlotte A. Brassey \\ The School of Science and the Environment, Manchester Metropolitan University, Manchester, M15 6BH, UK \\ 〈c.brassey@mmu.ac.uk〉
}

\begin{abstract}
Body mass is a key parameter for understanding the physiology, biomechanics, and ecology of an organism. Within paleontology, body mass is a fundamental prerequisite for many studies considering body-size evolution, survivorship patterns, and the occurrence of dwarfism and gigantism. The conventional method for estimating fossil body mass relies on allometric scaling relationships derived from skeletal metrics of extant taxa, but the recent application of three-dimensional imaging techniques to paleontology (e.g., surface laser scanning, computed tomography, and photogrammetry) has allowed for the rapid digitization of fossil specimens. Volumetric body-mass estimation methods based on whole articulated skeletons are therefore becoming increasingly popular. Volume-based approaches offer several advantages, including the ability to reconstruct body-mass distribution around the body, and their relative insensitivity to particularly robust or gracile elements, i.e., the so-called 'one bone effect.' Yet their application to the fossil record will always be limited by the paucity of well-preserved specimens. Furthermore, uncertainties with regards to skeletal articulation, body density, and soft-tissue distribution must be acknowledged and their effects quantified. Future work should focus on extant taxa to improve our understanding of body composition and increase confidence in volumetric model input parameters.
\end{abstract}

\section{INTRODUCTION}

Body mass is one of the most fundamental properties of an organism. Important aspects of physiology (metabolic rate, growth rate), biomechanics (running speed, posture), ecology (population densities, ecological niches), and behavior (predator-prey interactions, mating systems) are strongly influenced by overall body size (Schmidt-Nielsen, 1984 and references therein). Body mass is, therefore, a prerequisite for many studies within the field of modern comparative biology, and is particularly well documented for extant mammals and birds (Silva and Downing, 1995; Dunning, 2007).

The significance of body size has not been lost on paleontologists, and efforts to reconstruct the mass of extinct species span more than a century of academic research (Gregory, 1905). By turning to the fossil record, insight can be gained into broad evolutionary trends over time, e.g., rates of body-size evolution (Benson et al., 2014), extinction vulnerability as a function of body size (McKinney, 1997), and an appreciation for extremes in body size as characterized by phyletic dwarfism (Roth, 1990) and gigantism (Moncunill-Solé et al., 2014).

The application of computational and imaging techniques (e.g., computed tomography, surface laser scanning, and photogrammetry) has come to characterize the recently emerged field of 'virtual paleontology' (Sutton et al., 2014 and references therein). Alongside colleagues from a broad range of disciplines within paleontology spanning taxonomy, functional biomechanics, and comparative anatomy, researchers endeavoring to reconstruct fossil body 
mass have quickly embraced new digital approaches. This review provides a barometer for the current application of such three-dimensional (3-D) imaging techniques to the problem of fossil mass estimation. Here, I focus almost entirely on vertebrates because this is where the vast majority of recent research is centered, although invertebrates are considered in the future directions section. I critically assess the merits of volumetric approaches relative to traditional body mass predictive techniques, and highlight outstanding issues that remain unresolved with respect to digital reconstruction methods. In common with other virtualpaleontology techniques, volumetric mass estimation is potentially a very powerful approach, not just in terms of the novel questions that can be addressed, but also as a means of improving data sharing and reproducibility. It is essential, however, that the assumptions inherent within these techniques and the sensitivity of the approach to our skeletal reconstructions are acknowledged, and that we justify the application of volumetric methods beyond simply their novelty.

\section{BACKGROUND}

Even following the recent emergence of virtual paleontology, the most common approach to estimating fossil body mass remains regression-based predictive models (Damuth and MacFadden, 1990 and references therein). Such models exploit a tight allometric relationship between the dimensions of a given skeletal element or elements and known body mass in an extant calibration dataset. Best-fit models (typically linear fits to log-transformed data, but see Packard et al., 2009) are applied to modern datasets, and the resulting equations used in a predictive capacity on fossil material (Fig. 1). Dimensions used for body-mass prediction are often derived from elements experiencing weight bearing during locomotion, including femoral and humeral circumference (Anderson et al., 1985; Campione and Evans, 2012), femoral head breadth (Ruff et al., 1991), and glenoid diameter in flying birds (Field et al., 2013). Cranial metrics have also been used for mass prediction (Aiello and Wood, 1994; Wroe et al., 2003; Spocter and Manger, 2007).

As exemplified by their popularity, regressionbased body-mass prediction tools have a number of advantages over potential alternatives. By virtue of their simplicity, allometric equations can be generated

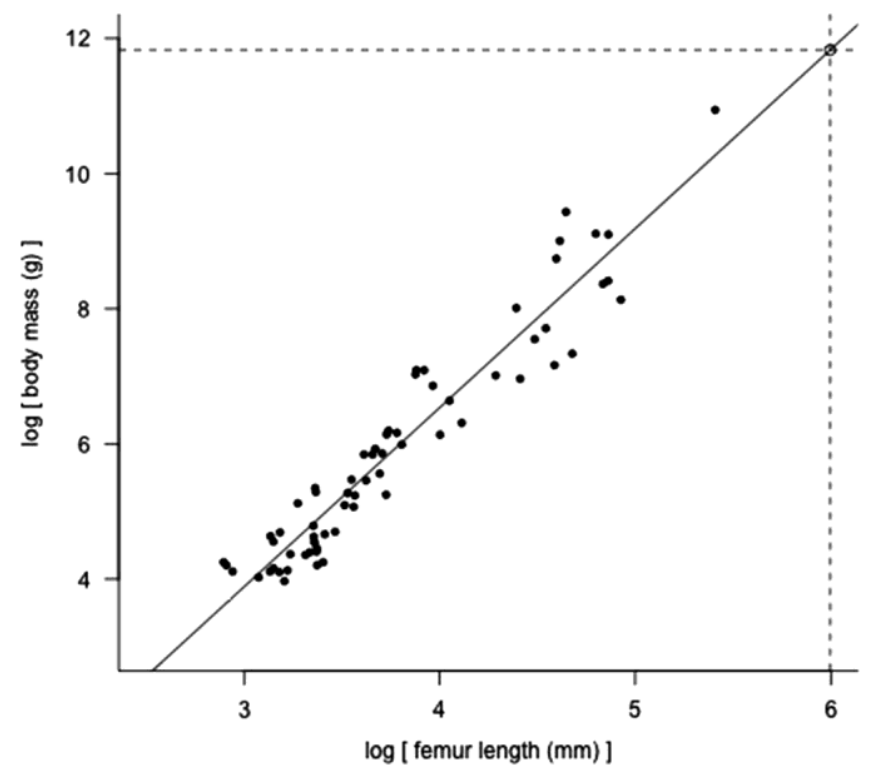

FIGURE 1.-An example of the traditional allometric approach to body-mass estimation. Log femur length is plotted against log body mass for a range of modern Glires (solid circles; data taken from Campione and Evans, 2012), and an OLS regression performed. Open circle represents the femur length of the giant rodent Phoberomys pattersoni (Mones, 1980) (402 mm, as reported by Millien and Bovy, 2010). Application of this predictive model results in a body-mass estimate of $137 \mathrm{~kg}(95 \% \mathrm{CI}=67-400 \mathrm{~kg})$ without correction for the effect of arithmetic vs. geometric means. Mass estimates for P. pattersoni published elsewhere range from $247 \mathrm{~kg}$ (Millien and Bovy, 2010; based on femur length), to $460 \mathrm{~kg}$ (Millien and Bovy, 2010; based on femur diameter), to $700 \mathrm{~kg}$ (Sanchez-Villagra et al., 2003; based on femur diameter). This highlights the sensitivity of the traditional allometric approach to the choice of skeletal element and modern reference sample.

for large modern datasets using straightforward caliper measurements, and as such, require little prior training. Regression-based techniques are also largely objective, involving minimal user input and no assumptions regarding the presumed appearance of the fossil taxa. Perhaps most importantly, such predictive equations can be applied to incomplete fossil remains. Given that the fossil record is extremely fragmentary, a body-mass prediction technique must be applicable to a small number of isolated elements for it to be widely utilized to answer broad evolutionary questions. In instances when only single elements are preserved, traditional allometry remains the most valid approach by virtue of being the only feasible approach.

However, disadvantages of traditional allometrybased body-mass estimation tools do exist. The apparent simplicity and lack of training required for 
the approach can increase the risk of misapplication or misunderstanding of statistical techniques (Smith, 1993; Kaufman and Smith, 2002; Smith, 2009). Additionally, when more than one fossilized element is available for study, some subjectivity is still required to determine which bone metric will be used as the basis for body-mass estimation, and which modern group ought to comprise the calibration dataset. As an extreme example, body-mass estimates for the giant ground sloth Megatherium americanum Cuvier, 1796 span from 0.5 to 97 tons when applying predictive equations derived from the same modern dataset, but based on the transverse diameter of the radius and femur respectively (Fariña et al., 1998). Both are weight-bearing long bones (assuming quadrupedality; but see Fariña et al., 2013) and might reasonably be considered reliable elements on which to base body-mass estimates of the giant ground sloth, despite the disparity in the final estimates. Furthermore, the ability to apply body-mass prediction equations to fragmentary material is not necessarily an advantage, because one can be left at the mercy of uncertainties in taxonomic affiliation, ontogenetic status, or potential taphonomic deformation when restricted to a single element.

The need to extrapolate a given relationship beyond the bounds of modern species is a frequent occurrence in paleontology. Fossil 'giants' and 'dwarfs' are a favorite subject of paleobiological analyses, presumably due in part to their extremes in body size, and body mass is regularly a focus of attention (Roth, 1990; Wroe et al., 2004; Millien and Bovy, 2010; Moncunill-Solé et al., 2014). However, mass predictions that require extrapolation beyond the range of modern taxa suffer from rapid widening of confidence intervals, and the lack of evidence for a given linear relationship holding true beyond extant species requires that such analyses be treated with extreme caution (Smith, 2002).

In addition, traditional regression techniques are currently limited to providing solely a single scalar value for mass, with no indication as to how this mass is distributed around the body. Center of mass is the mean position of mass within the body, and has proven important within the field of paleontology for estimating the distribution of weight on load-bearing long bones (Alexander, 1985; Henderson, 2006), buoyancy and instability in aquatic environments (Henderson, 2004), and for interpreting evolutionary trends in locomotor biomechanics (Allen et al., 2013). Similarly, segment inertial properties describe the distribution of mass around axes within a body segment, and are crucial in understanding how moments and angular accelerations act around a body. In practice, they become important in paleontology when conducting multibody dynamic analyses of locomotion or feeding (Sellers and Manning, 2007; Hutchinson et al., 2007; Bates et al., 2010; Snively et al., 2013). Both the center of mass and inertial properties are important mass parameters, but cannot be estimated using traditional regression approaches alone.

Finally, regression-based techniques are vulnerable to biasing by fossil species characterized by disproportionately robust or gracile features relative to the modern calibration dataset. An exaggerated example is the elongated canine tooth of the sabertoothed cat Smilodon. Found in isolation, such a large tooth might be erroneously interpreted as originating from an extremely large feline, and a cuspid-toothbased predictive model would produce very high body-mass estimates. When considered in the broader context of a complete skeleton, such an approach would clearly be inappropriate, but often, the distinction is much less obvious. For example, body masses of the extinct moa birds of New Zealand have frequently been reconstructed on the basis of hind-limb bone dimensions (Dickison, 2007; Worthy and Scofield, 2012; Olson and Turvey, 2013; Attard et al., 2016), despite qualitative [Dinornis robustus (Owen, 1846), literally 'robust terrible bird'; and Pachyornis elephantopus Owen, 1856, 'elephantfooted thick bird'] and quantitative (Alexander, 1983a, c) evidence of moa limb bones being unusually proportioned compared to extant ratites. Similarly, Haynes (1991) observed fossil mastodons to possess relatively more robust limb bones than modern elephants of similar overall size, potentially resulting in mass overestimates exceeding $100 \%$ if used as a basis for body-mass prediction. Crucially, in instances when fossil species are represented solely by single elements, any resulting reconstruction of total body size should therefore be regarded as extremely speculative (e.g., Braddy et al., 2008 versus Kaiser and Klok, 2008).

\section{VOLUMETRIC METHODS}

As part of a broader trend toward virtual paleontology (Sutton et al., 2014), 'volumetric' fossil body-mass 
estimation techniques have experienced a recent surge in interest (see below). Here, I define a volumetric body-mass estimation technique as any approach seeking to predict the body mass of a fossil species using volume as a proxy (physiological volume or otherwise). Although this recent burst of activity owes much to increasingly affordable and user-friendly digital 3-D imaging technologies and software, to some degree it constitutes a revival of a technique first applied over 100 years ago (Gregory, 1905).

\section{Physical sculpting}

Many of the earliest published mass estimates of dinosaurs were derived from sculpted scale models. Gregory (1905) constructed a one-sixteenth scale, 'fleshed-out' reconstruction of Brontosaurus excelsus Marsh, 1879 (AMNH 460; now referred to as an 'indeterminate apatosaurine"'; Tschopp et al., 2015) by "infer[ring] the external contours of [the] animal from its internal framework' (Gregory, 1905, p. 572). The resulting model was immersed in water, its volume estimated via displacement, and scaled back up to original size in accordance with the scaling factor. To convert volume to mass, the subsequent stage necessarily requires an estimate for body density. In 1905, the author assumed Brontosaurus to have been negatively buoyant 'in order to enable it to walk on the bottom along the shores of lakes and rivers' (Gregory, 1905, p. 572), and assigned a density of $1100 \mathrm{~kg} / \mathrm{m}^{3}$. Although interpretation of sauropod paleoecology shifted markedly over the following century, it is noteworthy that the uncertainty associated with assigning body densities is a common concern for volumetric body-mass estimation that remains unsatisfactorily addressed today. Furthermore, it is interesting to note that the body volume reconstructed by Gregory in 1905 is actually very similar to recent sauropod reconstructions. Bates et al. (2015) reconstructed the mass of Apatosaurus louisae (Holland, 1915) (length 21-22 m) as 27 tons assuming a density of $850 \mathrm{~kg} / \mathrm{m}^{3}$ using a recent digital volumetric technique (discussed below). Applying the same density to the apatosaurine (length $20 \mathrm{~m}$ ) results of Gregory (1905) with an estimate of 29 tons, indicates that this early reconstruction was not markedly different from what we perceive today as a reasonable body volume for a sauropod dinosaur.

Following the pioneering work of Gregory (1905), physical scale models continued to be used as a basis for mass estimation until relatively recently (Colbert, 1962; Alexander, 1983a, b, 1985; Kitchener, 1993; Farlow et al., 1995; Paul, 1997; Christiansen, 1997, 1998; Christiansen and Paul, 2001; Mazzetta et al., 2004). The majority focus on nonavian dinosaurs and take a very similar approach, differing only in details of volume estimation. Colbert (1962) determined the volume of dinosaur models via displacement of sand, whereas most others followed the approach of Alexander (1983b), in which volume was determined by weighing the models in both air and water. The volumetric analysis of Alexander (1985) is particularly noteworthy for being the first attempt to quantify both the body mass and center of mass of dinosaur species using this approach, including the incorporation of hypothetical lung cavities.

Early sculpted volumetric models overcame some of the drawbacks now associated with allometric predictive equations. The construction of physical models is relatively straightforward and requires no statistical analyses. There is no uncertainty regarding which modern group ought to be used as a calibration dataset, and extrapolation of an allometric relationship beyond the range of extant taxa is not necessary. Furthermore, mass predictions based on scale models incorporate information from multiple skeletal elements, thus minimizing the potential for biasing from an unusual skeletal element, and additional data on mass distribution is also obtainable.

Nonetheless, physical sculpting of clay models undeniably involves some degree of artistic license over the extent and positioning of soft tissues around the skeleton. Reconstructions are liable to vary depending on the individual researcher creating the model, and their very nature as physical constructions ensures that the sharing of data and reproduction of results is difficult to achieve. Additionally, the reliability of any volume-based body-mass estimate rests on the reliability of the underlying skeletal reconstruction. Although scale models are sculpted to match the approximate $\mathrm{p}$ cbadmin skeletal material, verifyin $D: 20170209122127 Z 09 / 02 / 2017$ 12:21:27 skeleton is problematic. approaches to mass es advances in imaging tech same density to the AMNH apatosaurine (length $20 \mathrm{~m}$ ) of Greogory skeletal models as a b: (1905) results in an estimate of 29 estimation.
Should read more like: "Applying the tons, indicating that this early reconstruction..." 


\section{Geometric slicing}

Early volumetric studies of pterosaurs marked a shift away from clay-sculpted scale models and toward an arguably more quantitative method of body-mass estimation in paleontology. The 'geometric' approach arose from the realization that 'the best way to arrive at a valid figure is to split the body up into a large number of small pieces and to estimate the weight of each separately' (Heptonstall, 1971, p. 66).

Although the initial study by Heptonstall (1971) was somewhat lacking in methodological detail, Bramwell and Whitfield (1974) created a reconstruction of Pteranodon built in the form of scaled engineering drawings based on several specimens. Simple geometric shapes (cones, cylinders, and spheres) were fitted to the head and limbs, the neck and trunk were subdivided into a series of slices represented as cylinders, and total body volume was calculated as the sum of segment volumes. Interestingly, the authors appreciated the considerable degree of pneumatisation likely present within the pterosaur body and its probable impact on body density. They took the notable step of quantifying percentage airspace occupying the necks of both an extant birds and reptiles as a guide, a property that remains poorly documented in modern species to this day. However, the density values assigned to the body cavity were, in the words of the authors, a 'guess' (Bramwell and Whitfield, 1974, p. 537), and extreme upper and lower values were also incorporated into the analysis to act as bounds to the mass estimate. This represents one of the first 'sensitivity analyses' within the discipline of volumetric fossil body-mass estimation, in which the impact of uncertainties in input parameters on resulting model outputs were quantified. More recently, sensitivity analyses have become ubiquitous in fossil volumetric reconstructions (see later discussion). The geometric body-mass estimation technique pioneered by Bramwell and Whitfield (1974) was expanded by Brower and Veinus (1981) to include 16 species of pterosaurs for the purpose of estimating wing loadings. Likewise, Hazlehurst (1991) and Hazlehurst and Rayner (1992) built on this approach by calculating predictive allometric relationships between the volumes of simple fitted shapes and the length of their underlying skeletal components for a range of pterosaurs, thus enabling a more rapid application of their volumetric technique to additional specimens.
This simplified geometric-slicing approach subsequently formed the basis of the more sophisticated 3-D mathematical slicing technique of Henderson (1999), which has been widely applied to a range of fossil vertebrates. Three-dimensional mathematical slicing requires dorsal and lateral two-dimensional (2-D) reconstructions of the fossil species of interest, comprising a fleshed-out, soft-tissue contour outlining an articulated skeleton. Skeletal reconstructions are typically derived from illustrations digitized from elsewhere in the literature, with additional information from photographs of mounted skeletons and/or linear measurements. Straight lines are drawn across 2-D profiles in a computer-aided design (CAD) package, and their intersections with the edge of the body contour exported as coordinate data. The intercept data are then used to define the major and minor radii of a series of elliptical slices along the body, with each pair of slices defining a volumetric 'slab' with parallel/subparallel ends (Henderson, 1999). An illustration of mathematical slicing is shown in Figure 2, in which the technique is applied to a dorsal and lateral view of the Smithsonian X3D model of the wooly mammoth, Mammuthus primigenius (Blumenbach, 1799) (USNM 23792; model available at http://3d.si.edu). The same mammoth model is applied throughout this review to illustrate various volumetric reconstruction techniques. Zero-density voids representing air-filled cavities can be created and mass properties calculated. It should be noted that, at the same time, Hurlburt (1999) developed a very similar, 'double integration' method for volumetric reconstruction with applications to mass estimation in pelycosaurs, although this study failed to incorporate regional variations in body density.

The Henderson (1999) technique has been utilized on a range of fossil vertebrate groups. Mathematical slicing has been applied to theropod dinosaurs, both as a means of calculating center of mass and rotational inertia (Jones et al., 2000; Christiansen and Bonde, 2002; Henderson and Snively, 2004) and simply for the purpose of estimating a scalar value for body mass (Therrien and Henderson, 2007). The latter study is notable for combining aspects of both volumetric and traditional allometric mass estimation techniques. Therrien and Henderson (2007) regressed volumebased body-mass estimates against specimen skull lengths to derive a skull-based predictive equation for 

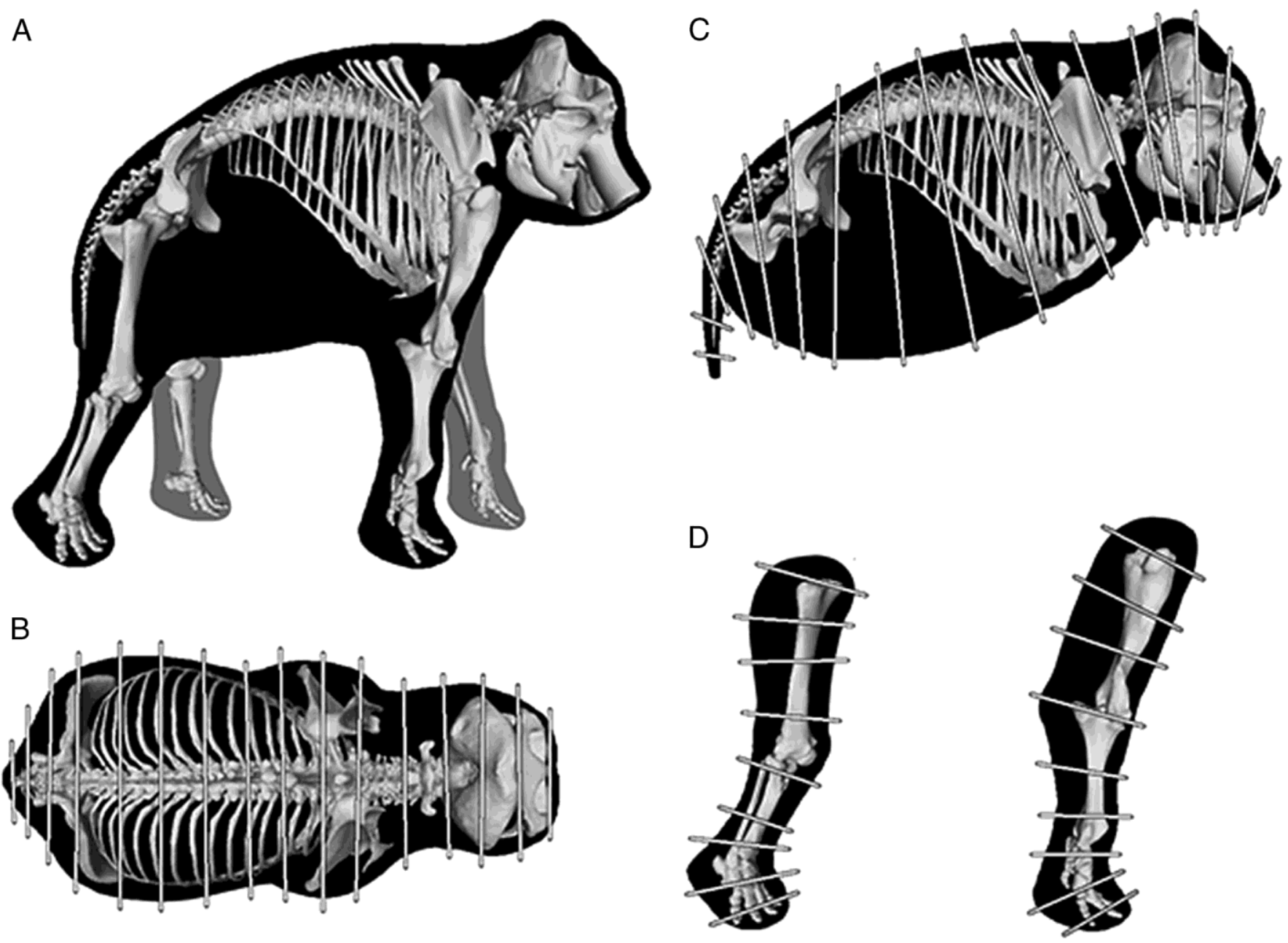

FIGURE 2.-The 'mathematical slicing' technique applied to Mammuthus primigenius: (A) body outline (black) graphically reconstructed around the skeleton, based on knowledge of soft-tissue distribution in extant mammals; (B-C) dorsal and lateral view of axial skeleton subdivided into series of slabs with subparallel ends; (D) legs are processed separately, and also require frontal views to determine slab geometry. The location at which lines transect the body contour are used to define a series of ellipses, with sequential ellipses forming volumetric slabs.

application to less-complete theropod dinosaurs, e.g., carcharodontosaurids and spinosaurids.

Sauropod dinosaurs have also been the subject of mathematical slicing either for the purpose of a straightforward mass estimate (Mazzetta et al., 2004) or to calculate centers of mass and buoyancy and hence make inferences regarding stability and body posture in an aqueous environment (Henderson, 2004). As access to computer resources has improved and users have become progressively more competent with $\mathrm{CAD}$ packages, models have become increasingly detailed. The reconstructions of Brachiosaurus and Diplodocus by Henderson (2006) incorporated paired ellipsoids throughout the axial skeleton, representing cervical, thoracic, and abdominal air sacs. The resulting mass estimates still relied on traditional allometric equations to some extent with sauropod lung volume estimated on the basis of a previously published avian scaling equation (Schmidt-Nielsen, 1984).

Mathematical slicing has been used to investigate the effect of dermal armor and cranial ornamentation of the center of mass in ornithischian dinosaurs (Maidment et al., 2014), and has been applied to pterosaurs to calculate mass (Henderson, 2010), and buoyancy and floating posture when on the water surface (Hone and Henderson, 2014).

Compared with the physical sculpting of scale models, the mathematical slicing technique has several advantages. By basing 3-D models on previously published figures and/or making orthographic reconstructions available alongside publication, an analysis can be subsequently repeated and body-mass estimates 
validated. Furthermore, increasingly complex air-sac systems or regions of variable tissue density can be incorporated into the model, potentially improving the accuracy of calculated mass properties. Mathematical slicing also improves on earlier geometric models by advancing beyond fitting simple objects (cylinders, cones, etc.) to include more realistic shape variation within functional units. For example, the shank can be modeled as bulging proximally with extensive muscle volume, and tapering distally to a slender tendinous region. Such local variations within the limbs are likely to be of considerable importance when calculating segmental inertial properties, and center of mass.

Mathematical slicing does, however, assume that cross sections of the body can be approximated as ellipses. Although this might hold true in the thoracic region, as highlighted by Henderson (1999), this is unlikely to be the case around the pelvis. Akin to scaled models, the accuracy of this approach ultimately depends on the underlying reconstruction. A volumetric reconstruction (Henderson, 2010) of the giant pterosaur Quetzalcoatlus northropi Lawson, 1975 based on figures from semitechnical literature was subsequently reported to have overestimated body length by a factor of 2.8 (Witton and Habib, 2010), which had a large effect on resulting body-mass estimates. Finally, the orthographic reconstructions on which this technique relies are still subject to some artistic license with regard to the volume of soft tissue placed beyond the bounds of the skeleton.

Although the mathematical slicing approach of Henderson (1999) has been the most widely adopted slicing technique, other similar approaches have been advocated. Seebacher (2001) developed an alternative 'polynomial' 3-D slicing technique, also utilizing orthographic 2-D reconstructions. From the lateral reconstruction, dorsoventral depth is measured sequentially along the length of the specimen. Half depth (y-axis) is plotted against length along the vertebral column (x-axis), and an eighth-order polynomial is fitted to the data (Fig. 3). By integrating along the length, the volume of the solid of revolution for the polynomial is calculated, effectively resulting in a 3-D rotational solid. This volume is multiplied by a uniform value for density to give a mass estimate for the axial skeleton. To account for the fact that animals rarely have continuous rotational symmetry around their long axis, the resulting mass is multiplied by a correction factor based on the mediolateral width: dorsoventral depth ratio of the reconstruction. Masses for the appendicular skeleton are then added by modeling the limbs as straightforward cylinders. Although this method can arguably be less mathematically involved than the Henderson (1999) approach, it does not allow for variable density structures and assumes an average width:depth value along the length of the animal.
A

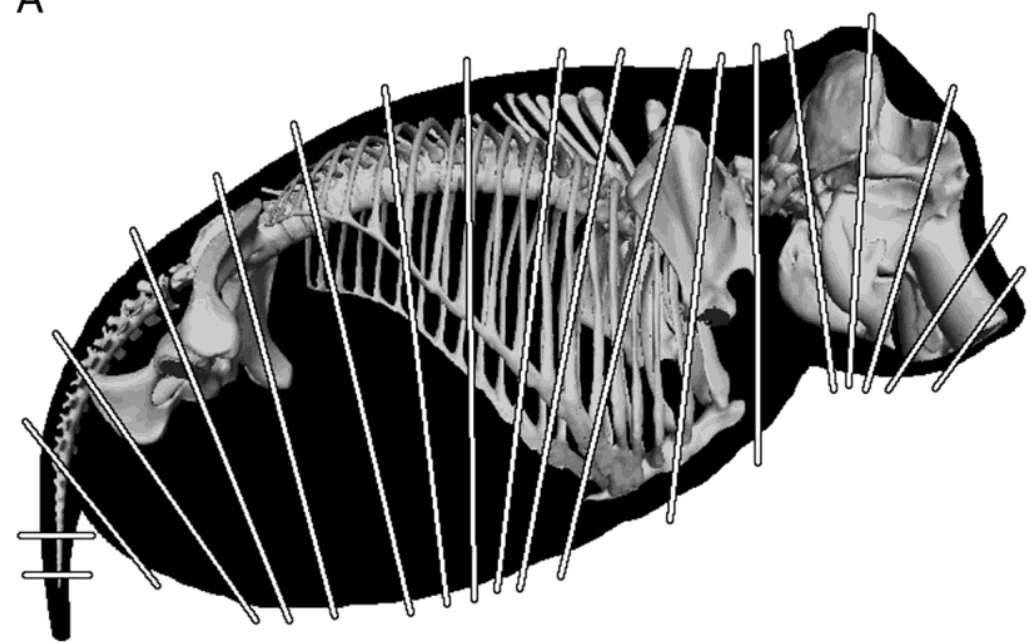

B

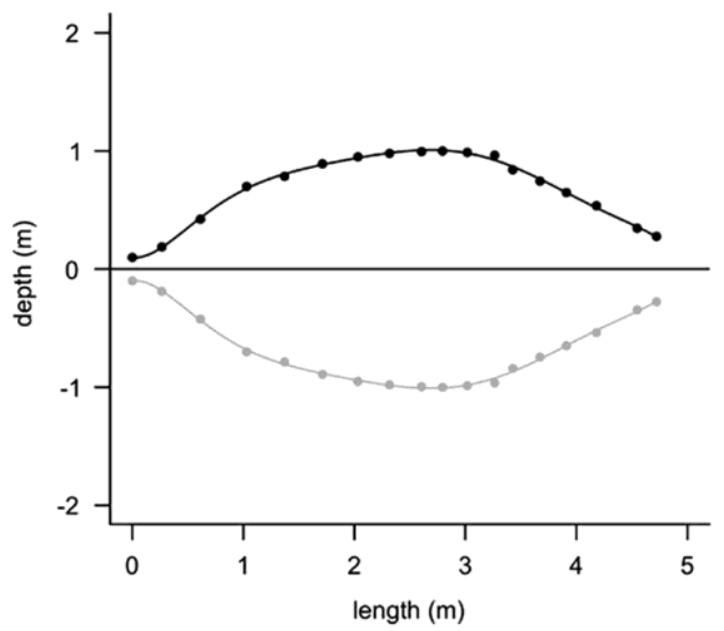

FIGURE 3.-The 'polynomial' technique applied to Mammuthus primigenius: (A) dorsoventral depth is measured at intervals along the length of the trunk, at right angles to the vertebral column; (B) half dorsoventral depth is plotted on the y-axis against length along the vertebral column on the $\mathrm{x}$-axis and an eighth-order polynomial fitted to the data. The solid of revolution is subsequently calculated by integrating along the length, and limb volume is added assuming a basic cylinder fit. 
Montani (2001) attempted to overcome a shortcoming of the implementation of mathematical slicing by Henderson (1999) by extending the technique to work on cross-sectional shapes other than ellipses. Height and width were calculated for each slice (a slice corresponding to one pixel in the original orthogonal images) along the length of the vertebral column, and superellipses fitted. The ultimate form of a superellipse depends on both the lengths of the major and minor semiaxes, and also on the value of $\mathrm{k}$, an exponent controlling the degree of 'swelling' exhibited by the shape. A $\mathrm{k}$ value of 2 produces an ellipse, whereas a $\mathrm{k}$ value approaching 4 produces a rectangle. Although the approach by Montani (2001) benefits from a higher slice count and the ability to incorporate low-density voids, the decision regarding which $\mathrm{k}$ value to assign is somewhat arbitrary and will vary both within an individual and between species.

\section{Rotational solids}

Although the aforementioned techniques all collect geometric data from orthogonal 2-D silhouettes, Gunga and colleagues recognized the value of collecting 3-D data directly from mounted museum skeletons. In their initial study, Gunga et al. (1995) applied 'stereophotogrammetry' to the Berlin mount of Giraffatitan brancai (Janensch, 1914) (previously Brachiosaurus) and produced a wireframe model of the specimen. This marked an important advance beyond silhouette-based reconstructions, but the approach still relied on simple geometric primitives (i.e., spheres, cones, and cylinders) being fitted to the wireframe to approximate the original soft-tissue contours of the animal. Additionally, although the image-acquisition stage of the photogrammetric process occupied 1-2 days per skeleton, the following registration and reconstruction phase originally took weeks (Wiedemann et al., 1999).

Gunga et al. (1999) improved on the initial study by utilizing laser scanning technology and CAD software to model a mounted skeleton of the sauropod Dicraeosaurus hansemanni Janensch, 1914. The method is discussed in more detail elsewhere (Wiedemann et al., 1999; Stoinski et al., 2011), and represents one of the earliest applications of surface laser scanning in the field of vertebrate paleontology. For the first time, a volumetric mass estimate was based on a point-cloud dataset and, despite relying on relatively new technology, was already considerably faster than stereophotogrammetry (Gunga et al., 1999). A similar 3-D point-cloud model of Plateosaurus engelhardti von Meyer, 1837 was later constructed using the same technique (Gunga et al., 2007). Despite improvements in the quality of the underlying dataset, both studies still used basic geometric primitives to approximate the fleshed-out appearance of the individual, resulting in models that appear bulky, with very barrel-like chests.

Interestingly, Gunga et al. (2008) returned to the Berlin specimen of Giraffatitan to repeat their estimate of body mass while applying new surface modeling approaches. Rather than simple geometric primitives, Gunga et al. (2008) applied rotational solids and nonuniform rational B-splines (NURBS) surfaces (see later discussion) to reconstruct the surface contours of the individual. Rotational solids (or solids of revolution) are generated by rotating a plane curve around an axis. Although their individual shape is necessarily restricted to having radial symmetry, Boolean operations to combine, subtract, or intersect multiple shapes allow for more complex body geometries to be obtained. Predicted body mass for Giraffatitan decreased to 38 tons, relative to the 74 tons estimated by Gunga et al. (1995). Part of this dramatic reduction was due to a change in assumed body density from $1000 \mathrm{~kg} / \mathrm{m}^{3}$ to $800 \mathrm{~kg} / \mathrm{m}^{3}$ for the sauropod. The authors attributed the remaining $\sim 20$ ton decrease to improved surfacing methods (rotational solids and NURBS vs. blocky geometric primitives), highlighting the sensitivity of this approach to surface modeling techniques.

\section{Nonuniform rational B-splines (NURBS)}

NURBS curves and surfaces are examples of analytic geometries, meaning that their shape is defined by mathematical functions. Ultimately, the shape of a NURBS curve or surface is determined by a set of control points, which do not necessarily themselves sit on the surface of the curve. Rather, the shape of the curve is influenced by the position of control points, and movement of a control point causes the nearby surface to also move as if attached by a spring. Adjusting the position of control points allows the shape of the object to be changed locally, and adding further control points can provide finer control over the shape of a specific region. Compared to the alternative (discrete geometry in the form of 
triangular meshes), NURBS perform better when creating complex surfaces, and appear 'seamless' rather than faceted. Importantly, because NURBS objects are mathematical functions, they effectively have an unlimited resolution, ensuring that they are useful when working across to a range of precisions. In practice, however, the shape of analytical geometries is typically estimated with a polyhedral mesh to allow visualization and calculation of volume within software, and NURBS are a standard surface-fitting function in most CAD packages, including Autodesk products (Autodesk, San Rafael, California, http://www.autodesk.com) and Rhino3D (McNeel Associates, Seattle, Washington, https://www.rhino 3d.com/).

The first fossil body mass reconstructed solely on the basis of NURBS was of a Tyrannosaurus rex Osborn, 1905 (MOR 555) cast (Hutchinson et al., 2007). The authors digitized landmarks across the axial region of the skeleton, and combined these data with preexisting 3-D data of the hindlimbs to construct a base model. Using custom-written software, basic B-spline solids (i.e., cylinders, boxes, etc.) were fitted around the bony extremities of body segments and subsequently pulled away from the skeleton by 'a few centimeters' (Hutchinson et al., 2007, p. 666) and reshaped via control points to achieve the desired geometry. Due to the flexibility of NURBS modeling, increasingly detailed, zero-density cavities (including the buccal cavity, cranial sinuses, trachea, and esophagus) could be incorporated into the model and any resulting calculations. Most importantly, Hutchinson et al. (2007) conducted an extensive sensitivity analysis quantify the effect of uncertainty in input parameters (e.g., segment/cavity shape and size) on estimates of body mass, center of mass, and inertial properties. Moving beyond the initial 'robust' vs. 'slim' form of sensitivity analysis (Bramwell and Whitfield, 1974), 29 different permutations of the T. rex model were generated by combining variations in torso, leg, and air-cavity dimensions. Interestingly, the authors found uncertainty in the volume occupied by the air-sac system did not have much of an effect on mass estimates, although center of mass calculations were more sensitive to this ambiguity.

Building on this work, Bates et al. (2009b) digitized five museum-mounted dinosaur skeletons using a LiDAR (Light Detection and Range) scanner, and undertook volumetric mass estimation. By utilizing long-distance laser scanning in public galleries, larger sample sizes could be achieved in a quick and efficient manner (five skeletons in one day), paving the way for broader interspecific/intraspecific studies of body size and center of mass evolution. The authors fit a series of 2-D NURBS circles along the length of the trunk in the commercial software Maya (Autodesk, San Rafael, California, http:// www.autodesk.com/products/maya/overview-dts?s tnt $=69290: 1: 0)$ and then loft a continuous surface between them, resulting in more contoured 3-D models than in previously studies (Fig. 4). This approach was subsequently extended to an exceptionally complete specimen of Allosaurus fragilis Marsh, 1877 by Bates et al. (2009a), on which the first sensitivity analysis of skeletal articulation was carried out. The effect of uncertainty in the skeletal mount was quantified by varying intervertebral spacing and mediolateral flaring of the ribcage, highlighting the particular importance of constraining trunk morphology in such models. Encouragingly, expanding/contracting the size of the ribcage mediolaterally resulted in only a $4-6 \%$ change in total predicted mass, and increased intervertebral spacing increased mass by only $2.5 \%$. It is assumed that shifting dimensions of internal air cavities in proportion with external contours negated potential changes in predicted body mass.

Mallison (2010) undertook the first volumetric mass estimation based solely on CT-scanned fossil material. The mass of Plateosaurus engelhardti was reconstructed using NURBS bodies fitted to the skeleton, which had itself been digitally rearticulated from 3-D models of isolated skeletal elements in Rhino3D. By basing volumetric models on digital articulations rather than pre-existing (sometimes outdated) museum mounts, conducting sensitivity analyses of the impact of skeletal articulation on resulting mass estimates becomes considerably more straightforward.

In their ontogenetic series of Tyrannosaurus rex reconstructions, Hutchinson et al. (2011) went a step further by considering the effect of investigator bias on volumetric mass estimates. Two groups contributed volumetric models of adult $T$. rex specimens reconstructed using NURBS modeling to the study, and one team consistently produced more 'fleshy' reconstructions than the other. On a practical scale, this difference was attributed to investigator 
A

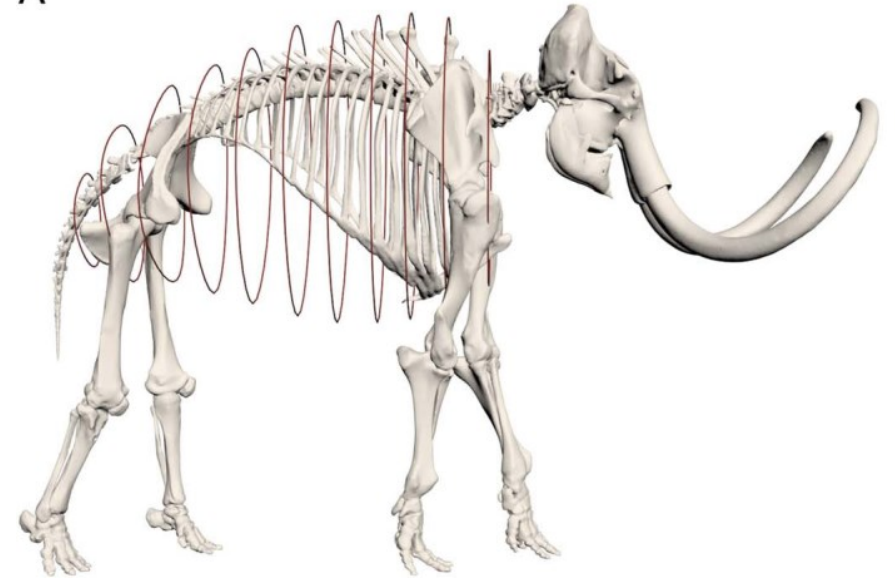

B

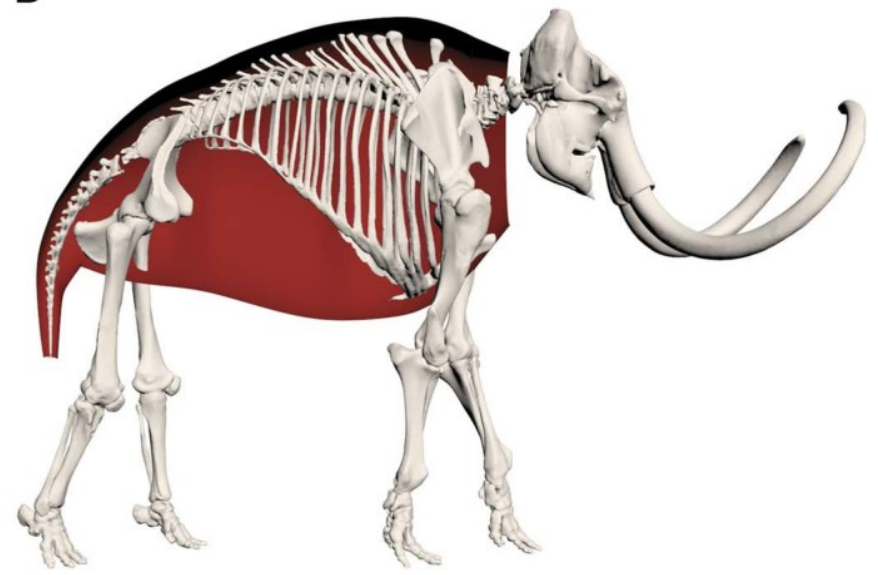

FIGURE 4.-NURBS object as fitted to the Mammuthus primigenius trunk: (A) a series of NURBS curves are fitted along the length of the trunk; (B) a NURBS surface is lofted between the curves to form a smooth-contoured, continuous skeleton. A cavity representing lung volume could also be sculpted to fit within the confines of the ribcage. This specimen of M. primigenius stands $\sim 3 \mathrm{~m}$ in height at the shoulder.

preference over the number of NURBs loops fitted around the skeleton, and hence the extent to which the soft-tissue surface tightly contoured the underlying skeleton. Ultimately, however, it exemplifies the subjectivity involved in digitally sculpting softtissue contours of an extinct species on the basis of skeletal material alone. Finally, Allen et al. (2013) applied this technique to generate an impressive dataset of 15 NURBS-based volumetric models of fossil theropods from which an evolutionary trend in center of mass was used to infer pelvic limb function within bird-line archosaurs.

To date, NURBS is the preferred technique for digitally sculpting the fleshy contours of extinct organisms. Alongside improved access to 3-D scan data (LiDAR and CT) and user proficiency with CAD software, sample sizes are increasing. As a result, the questions being addressed are progressively shifting from simply, 'How large was X species?' to arguably more sophisticated analyses, e.g., 'How did body size/shape evolve over time, or within a particular lineage?' The potential for digital rearticulation and reposing of older museum mounts ensures that volumetric models will remain contemporaneous with our understanding of the underlying organismal biology. Furthermore, their flexible digital nature allows for detailed sensitivity analyses to be conducted, elaborate internal voids to be incorporated, and for publication alongside journal articles within supplementary materials or online repositories.
Although more computationally sophisticated and visually appealing, NURBS modeling is effectively a digital equivalent of clay sculpting. And whereas practitioners undoubtedly rely on their extensive experience as animal anatomists, some artistic license is inevitably required. As highlighted by Hutchinson et al. (2011), there is little to be done about this subjectivity when sculpting fossil species, other than to recognize that it exists, and explicitly acknowledge it within our publications. Additionally, in the current drive toward constructing ever more realistic-looking models, it is important to find a balance between oversimplification (e.g., the fitting of basic cones and cylinders) and overcomplication (time-consuming sculpting with minimal impact on results). As an example, Hutchinson et al. (2007) did not attempt to fit NURBS objects around the tiny arms of T. rex, and instead added a small volume at the cranial edge of the coracoid, because doing so likely had minimal impact on resulting calculations. Fundamentally, the level of detail required will depend on the question being asked and the analysis being run, and sensitivity analyses play an important role in determining which parameters are stable/ sensitive to our modeling choices.

\section{Convex hulling}

All preceding volumetric techniques have sought to reconstruct the fleshed-out physiological volume of an extinct species, and incorporate assumed densities 
to estimate body mass. The convex hulling method described here was born out of a desire to avoid such subjective sculpting of soft-tissue volumes, and to instead develop a body-mass estimation technique that would both be objective and require minimal user intervention. The resulting approach is effectively a hybrid technique, combining both volumetric and linear bivariate approaches.

Working in 2-D, the convex hull of $\mathrm{n}$ set of points is the smallest convex polygon that encompasses $n$. More intuitively, an elastic band stretched around a set of nails hammered into a board will contract to produce the convex hull of said nails when released. The same applies in 3-D, with a minimum volume 'shrink-wrap' polygon fitted around a series of XYZ points in space. The convex hull is a fundamental construct of computational geometry, and in the past has been applied within the disciplines of biology (including home-range modeling; Scull et al., 2012; and canopy volume estimation; Auat Cheein and Guivant, 2014), path planning in robotics (Schulman et al., 2014), and collision detection in computer game design (Jiménez et al., 2001).

Sellers et al. (2012) first applied convex hulling to the problem of fossil body-mass estimation. Following from the Hutchinson et al. (2011) suggestion that future volumetric techniques might proceed by identifying consistent relationships between bonesurface contours and overlying fleshy contours, convex hulling instead attempts to establish a consistent relationship between convex-hull volume and total body volume in extant species. The articulated skeletons of 14 modern quadrupedal mammal species were LiDAR scanned and representative point clouds generated. Each skeletal point cloud was subdivided into 'functional units,' including head, neck, trunk, upper arm, lower arm, etc. Subdivision of the model at this stage is essential to achieve tight-fitting hulls around the skeleton, and can be achieved in commercial software (ReCap360, Autodesk, San Rafael, California, http://www.autodesk.com/products/recap360/overview; Geomagic, 3DSystems, Rock Hill, South Carolina, http://www.geomagic.com/en/) or freeware (Meshlab, http://meshlab.sourceforge.net/; Cignoni et al., 2008). Convex hulls are subsequently fitted around functional units, typically using the 'qhull' algorithm (Barber et al., 1996) as implemented in functions within $\mathrm{R}$ ('convhulln' function in 'geometry' package; Barber et al., 2015) or MATLAB ('convhulln' function; MathWorks, Natick, Massachusetts, http://www.mathworks.com/), or alternatively within Meshlab or Maya software (Fig. 5).

The convex-hull volume of each segment is summed to give a total convex-hull volume for the whole skeleton. At this stage, Sellers et al. (2012) multiplied this volume by an average mammal density of $894 \mathrm{~kg} / \mathrm{m}^{3}$ to give a value for 'minimum mass.' Minimum convex-hull mass was subsequently regressed against known body mass to produce a predictive bivariate equation. Sellers et al. (2012) forced the unlogged regression equation through the origin, resulting in an equation in the form $y=1.206 x$. Simply put, live body mass is expected to be consistently $21 \%$ greater than the mass defined by convex hulling. This relationship was then applied to a LiDAR model of the Berlin Giraffatitan, having fitted segmental convex hulls around the skeleton and multiplied volume by an assumed density of $800 \mathrm{~kg} / \mathrm{m}^{3}$ to derive minimum mass.

Compared to physical and digital sculpting techniques, convex hulling is relatively objective (but see later discussion), and requires very little training with regard to data processing. It also marks an improvement over traditional limb-bone-based predictive equations by incorporating data from the entire skeleton, rather than relying on single elements. However, convex hulling does require considerable investment in terms of generating an extant dataset of 3-D articulated skeletons, resulting in calibration equations often based on small sample sizes. Furthermore, in the original convex-hull work by Sellers et al. (2012), density values still had to be assigned for both the modern calibration dataset and the fossil species of interest.

Brassey et al. (2013) circumvented this density issue by directly regressing convex-hull volume against live body mass to generate a predictive equation. To estimate the body mass of moa birds (extinct ratites endemic to New Zealand), a predictive model based on LiDAR-scanned skeletons of modern ratites was derived. By directly plotting convex-hull volume against body mass, there was no need to directly assign a value for body density from the literature. However, there is an implicit assumption that the density of the fossil species will fall within the range of densities occupied by the modern species. This assumption is likely upheld in the case of moa birds and extant ratites, but might be 

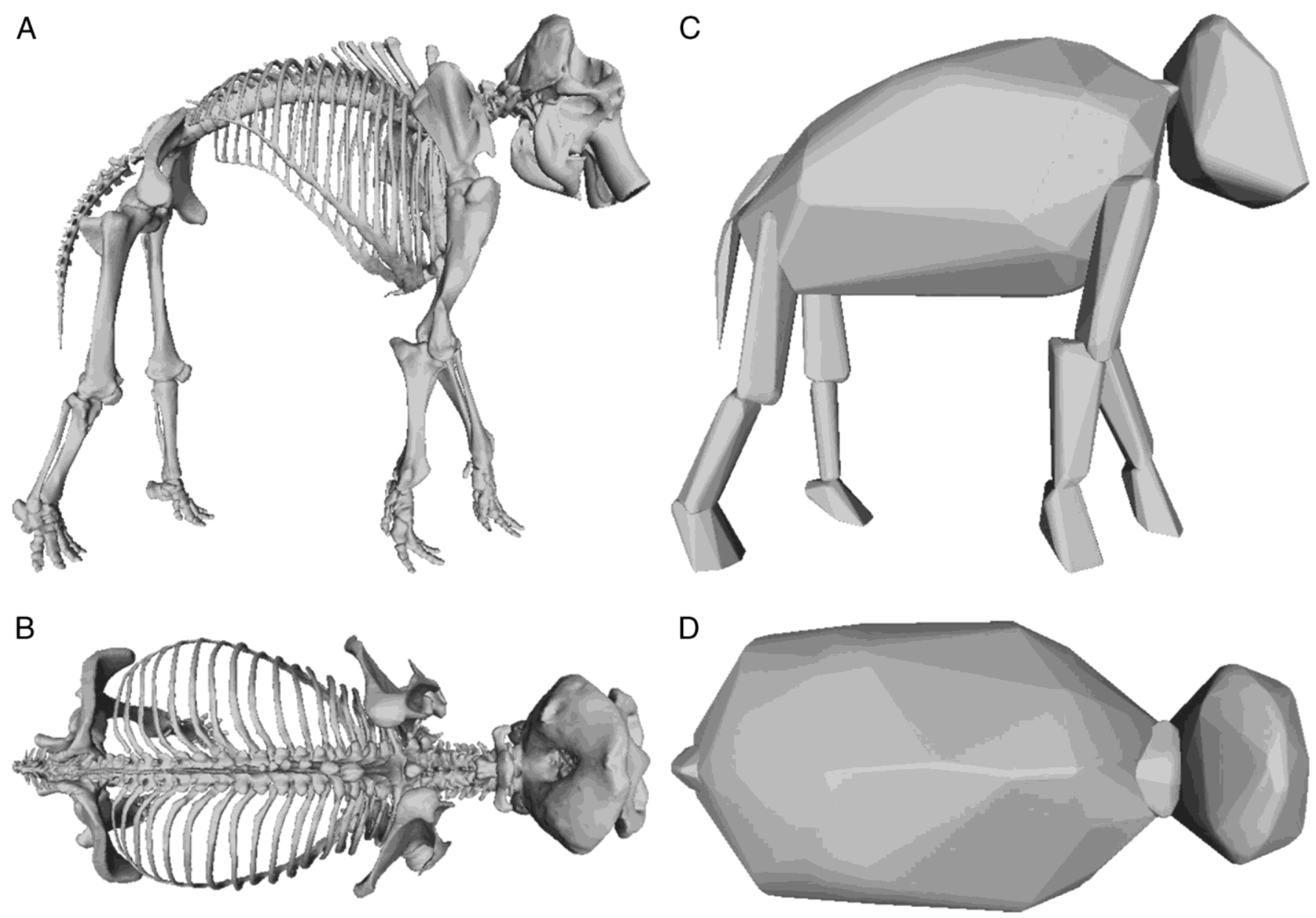

FIGURE 5.-Convex hulling applied to the Mammuthus primigenius skeleton: (A-B) lateral and dorsal views of the skeleton, respectively; (C-D) convex hulls fitted to the skeleton following subdivision into functional units. Note that the convex hull 'snaps-to' extremities of the trunk, typically the lateral margins of the shoulder and pelvis. Scale as in Figure 4.

problematic if reconstructing sauropods from a mammal-based equation, as by Sellers et al. (2012).

Brassey and Sellers (2014) extended this technique to compare the scaling of convex-hull volume to body mass in extant primates, nonprimate mammals, and birds. Importantly, this study includes a sensitivity analysis to quantify the effect of point-cloud density on the results of skeletal convex hulling. As in the case of Sellers et al. (2012), if several skeletons are segmented out of one large LiDAR scan, smaller individuals will comprise a lower number of points than larger specimens. Given that this phenomenon exists, it is reasonable to question whether the convex-hull scaling relationship of interest might be affected, and all models were downsampled to an equal number of points to investigate further. No significant difference was found between original convex-hull volumes and downsampled volumes, and the scaling exponents characterizing the relationship between convex-hull volume and body mass were similar between original and downsampled datasets. This result is unsurprising because a limited number of points are required to approximate a convex surface. Consider a circle and polygon of equivalent size: as the number of sides of the polygon increases, its area rapidly approaches that of the circle, then plateaus.

Additionally, the inser cbadmin D:20170209122257Z09/02/2017 12:22:57 point-cloud density is als Something wrong here.. they 'snap-to' the extrem given 'trunk' unit comprisi lumbar vertebrate, and pe fitted convex hull will li small number of points ld shoulder, pelvis, and dis between do not contrib (and hence volume) of the hull. This is beneficial in 
some respects because missing data located within the bounds of the hull does not negatively affect the reconstruction. However, in instances when the location of such extremities is uncertain (due to taphonomic damage or unreliable articulations), convex-hull volume is extremely sensitive to their positioning.

To quantify the effect of uncertainties in skeletal articulation, Brassey et al. (2015) applied the mammal-based regression of Sellers et al. (2012) to an exceptionally complete specimen of Stegosaurus stenops Marsh, 1887 (NHMUK R36730). The specimen was digitized as a disarticulated skeleton, and photogrammetry models constructed of each skeletal element, allowing for 'minimum' and 'maximum' versions of the articulated skeleton to be constructed. The 'minimum' model was characterized by vertebrae placed unrealistically close to one another and an extremely narrow ribcage, whereas the 'maximum' model possessed vertebrae spaced far apart and a broadly flaring ribcage. The 'preferred' intermediate model resulted in a body-mass estimate of $1560 \mathrm{~kg}$ $(95 \%$ prediction interval $[\mathrm{PI}]=1082-2256 \mathrm{~kg})$, whereas minimum and maximum models resulted in $1311 \mathrm{~kg}(95 \% \mathrm{PI}=916-1884 \mathrm{~kg})$ and $1894 \mathrm{~kg}$ $(95 \%$ PI $=1303-2760 \mathrm{~kg})$, respectively.

Interestingly, body-mass estimates calculated from a previously published predictive equation based on humeral plus femoral circumference (Campione and Evans, 2012) fell considerably above those based on convex hulling: $3752 \mathrm{~kg}(95 \%$ PI = $2790-4713 \mathrm{~kg}$ ). Application of this equation does not, however, account for the subadult status of the Stegosaurus specimen, as was determined by visible neurocentral sutures, fenestrae between the sacral ribs, and a lack of an external fundamental system in limb cross section. One can intuitively appreciate that individuals change shape as they age (adults are not perfectly scaled-up versions of juveniles), and the application of predictive equations to subadult specimens risks conflating ontogenetic scaling with interspecific scaling. The authors corrected for this phenomenon by applying developmental mass extrapolation (DME) (Erickson and Tumanova, 2000), in which a predictive equation is applied to a known adult individual of the same species and subsequently scaled down, assuming isometry of femur length (Brassey et al., 2015). Application of DME resulted in much-reduced mass estimates of 1823-
$2158 \mathrm{~kg}$ for the specimen using the Campione and Evans (2012) equation, overlapping with those based on volumetric models and highlighting the sensitivity of traditional allometry-based predictive models to uncertainty in ontogenetic status.

Convex hulling has since been applied to estimate the body mass of a range of fossil species, including extinct birds, mammals, and dinosaurs. The mass of the giant titanosaurian sauropod Dreadnoughtus schrani Lacovara et al., 2014 has been revised from an initial 59 tons (Lacovara et al., 2014) down to 28-38 tons (Bates et al., 2015) on the basis of convex hulling. Likewise, the predicted mass of the giant giraffid Sivatherium giganteum Falconer \& Cautley, 1836 has also been reduced from $3000 \mathrm{~kg}$ to $1246 \mathrm{~kg}$ using this technique (Basu et al., 2016). In both cases, a considerable portion of the skeleton was missing and required reconstruction, either through substitution of equivalent elements from related taxa and/or virtual manipulation of the convex hulls. In such instances, extensive sensitivity analyses are recommended to quantify the effect of said reconstructions on final body-mass estimates. Finally, all previous applications of convex hulling have relied on a dataset of modern 3-D skeletal models derived from LiDAR-scanned museum mounts. For the first time, Brassey et al. (2016) produced an extant calibration dataset generated entirely from CT-based 3-D models, in this case, a large interspecific sample of modern pigeons on which to base body-mass estimates of the dodo, Raphus cucullatus (Linnaeus, 1758). By restricting the modern dataset to CT-scanned carcasses, any uncertainty in skeletal articulation is negated (assuming that the cadavers are intact) and body mass is directly obtainable from weighing the specimen. This contrasts to the situation of using LiDAR-scanned museum mounts that are frequently outdated in posture and/or damaged, and often lacking in associated data (e.g., body mass).

Brassey and Gardiner (2015) explored the broader construct of 'alpha shapes' as a potential improvement over previous applications of convex hulling. Alpha shapes ( $\alpha$-shapes) are generalizations of the concept of convex hulls, yet their ultimate form depends both on the underlying point cloud and the value of alpha. Alpha values range from 0 to infinity, and define a suite of $\alpha$-shapes from 'fine' to 'crude', terminating in a convex hull when $\alpha=$ infinite. Depending on the value of $\alpha$ chosen, resulting shapes 

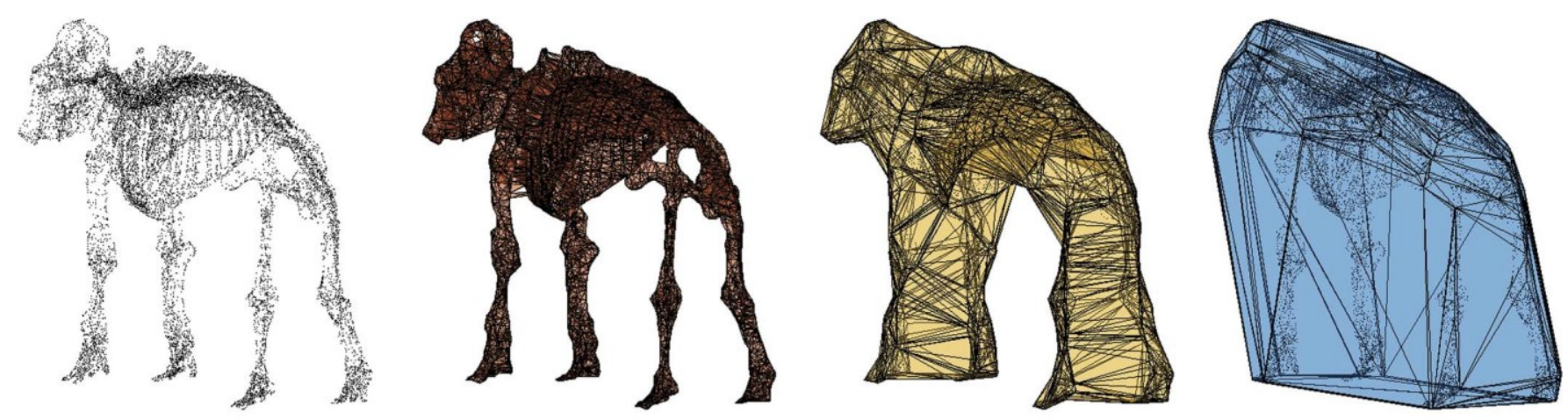

FIGURE 6.-Alpha shapes as fitted to the Mammuthus primigenius skeleton: (left to right) point cloud of the skeleton; 'finer' fit of alpha shape in which contours closely wrap around the skeleton; 'coarser' fit of alpha shape in which fore- and hindlimbs are joined together; convex hull fit of alpha shape when $\alpha=$ infinite. Scale bar $=1 \mathrm{~m}$.

can be concave in places and more closely sculpted to the underlying geometry (Fig. 6). Alpha shapes can improve on convex hulling by removing the need to arbitrarily subdivide the skeleton into functional units, and the contribution of a greater number of points to the overall form of the $\alpha$-shape reduces the influence of potential outliers. The results of Brassey and Gardiner (2015) were equivocal, however. Alpha-shapes regression models were characterized by high correlation coefficients, and produced mass estimates for the woolly mammoth and giant sloth in line with previous publications. However, the technique was shown to be sensitive to the posture of museum mounts, and was considerably more computationally expensive than straightforward convex hulling. Finally, it is worth reiterating that calculated a-shape volumes were used solely as an independent variable within a bivariate predictive equation. There was no attempt to reconstruct the fleshed-out contours of the organism, and the distribution of volume within the $\alpha$-shape almost certainly does not reflect that of the live animal.

\section{Skeletal volume}

Previous allometric analyses have found an extremely close correlation between body mass and dry skeletal mass in extant birds and mammals (Prange et al., 1979). This relationship is of particular interest to those wishing to estimate the mass of pterosaurs because it circumvents the need to estimate soft tissue pneumasticity/body density. Yet throughout the process of fossilization, the density of bone is increased, so such a model is clearly not directly applicable to extinct taxa. Witton (2008) overcame this problem by using a volumetric approach, fitting simple shapes (e.g., cones, prisms, and hollow cylinders) to disarticulated pterosaur skeletal elements, multiplying the estimated bone volume by a literature value for bone density to calculate skeletal mass, and entering values into the original Prange et al. (1979) equation. However, Martin-Silverstone et al. (2015) repeated the Prange et al. (1979) analysis with an improved dataset of modern birds, and found phylogeny to be a strong control over bone mass within the sample. In light of these results, the use of bone volume in a predictive capacity is not recommended beyond closely related taxa, in this case, Neornithine birds.

\section{Outstanding Issues with Convex Hulling}

Within the broad discipline of paleontology, there is ongoing concern over the use of the present to reconstruct the past. There is a danger that we 'condemn the past to be like the present' (Pagel, 1991, p. 532) and for the organisms we construct to be averaged 'everyanimals.' We might consider volumetric body-mass estimation techniques (e.g., convex hulling) to be less vulnerable to this phenomenon compared to traditional allometric predictive equations because our models could reflect more fundamental biomechanical or physiological processes constraining the volume of soft tissue accommodated around the skeleton. That being said, there remain numerous outstanding issues with the methodology and application of convex hulling that require further thought. With convex hulling, we initially set out to combine the best 
of both worlds from volumetric and allometric predictive models, but we have inevitably incorporated negative aspects of both approaches.

Mass distribution.-As highlighted in the above review, many volumetric reconstructions of fossil species are undertaken with the purpose of estimating either center of mass or segment inertial properties, with scalar values for total body mass being an associated byproduct. Yet, unlike techniques such as mathematical slicing or rotational solids, convex hulling does not set out to reconstruct the fleshy contours of the organism, and simply 'snaps-to' the bony extremities. In regions with extensive musculature (e.g., thighs), convex-hull volume will underestimate 'fleshed-out' volume to a greater degree than in regions with less soft tissue (e.g., shank and metatarsals; Fig. 7). Although not an issue when estimating total body mass, this will significantly affect calculated inertial properties. In their forwarddynamic simulation of locomotion in the sauropod dinosaur Argentinosaurus, Sellers et al. (2013) 'reflated' the convex hulls around the skeleton by $21 \%$ to account for the previously calculated volume of missing mass. This volume was added solely to the thigh and upper arm segments to account for this effect, although this decision was admittedly somewhat arbitrary.

The application of a mammal-based convex-hull equation to nonmammalian taxa (e.g., dinosaurs) can also be questioned on the grounds of mass distribution. The original Sellers et al. (2012) model found $21 \%$ of fleshed-out mass lay beyond the extent of fitted convex hulls, and assumed the same proportion to characterize the fossil species of interest. In reality, fossil pseudosuchians and nonavian dinosaurs were likely in possession of a large volume of muscle extending from the hind limb to the tail, predominantly the M. caudofemoralis longus. A mammalbased equation fails to account for this musculature, and the $21 \%$ 'missing mass' of Sellers et al. (2012) might therefore be an underestimate when applied to such species. More modern data on the distribution of soft tissue around the skeleton (e.g., those garnered from CT) should inform volumetric reconstructions in the future.

Extrapolation.-Although considered volumetric techniques here, both convex-hull volume and skeletal volume are ultimately entered as independent variables in bivariate predictive equations, just as femoral circumference or molar height have been used. As such, extrapolation of these predictive relationships beyond the bounds of extant taxa should be regarded with extreme caution. Simply put, one must assume a sauropod dinosaur held a similar proportion of soft tissue beyond the extent of skeleton-defined convex hulls as do the modern calibration taxa, which is almost always impossible to validate. Furthermore, prediction intervals widen rapidly as the model is extrapolated, emphasizing the particular importance of reporting uncertainty alongside fossil body-mass estimates, especially when dealing with extremely large taxa.

Density.-Despite fossil body-mass estimation now being a well-established practice in vertebrate paleontology, the assignment of body density remains a contentious issue. Although convex hulling does not explicitly require a density value to be
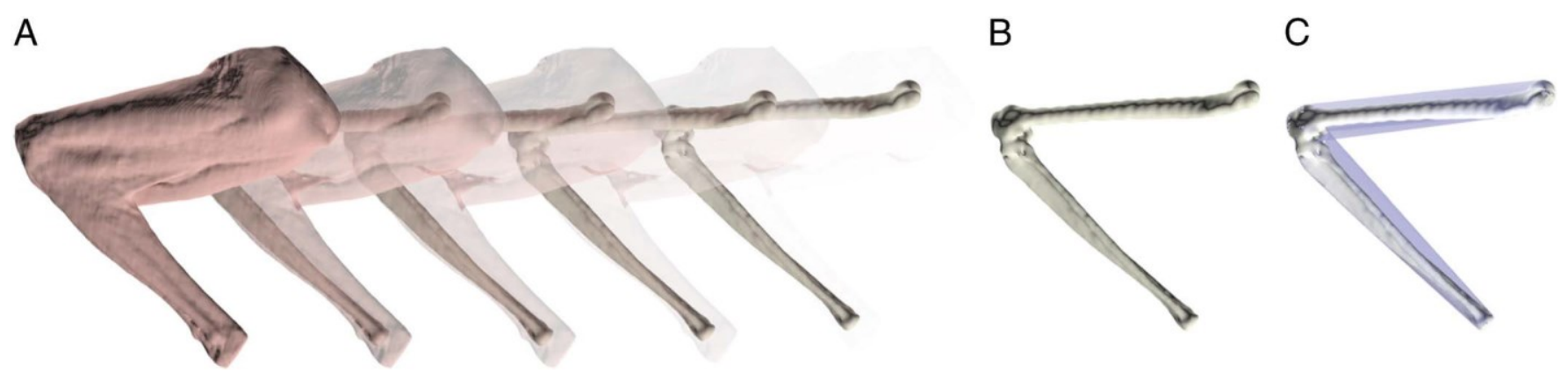

FIGURE 7.-CT rendering of the soft tissue contour of a squirrel monkey, Saimiri sciureus (Linnaeus, 1758): (A) hindlimb, illustrating the extent of soft tissue around the hind limb and its subsequent removal to leave only the underlying skeletal elements to which convex hulls are fit; (B) the femur and tibia isosurfaced from the scan; (C) corresponding convex hulls fitted to the limb bones outlined in blue. Note that considerably more 'missing mass' is absent around the femur than the tibia. 
assigned, it does still make assumptions regarding fossil body density. At present, well-designed sensitivity analyses are applied to bracket uncertainty in fossil density values, and the onus is increasingly shifting toward improving data for extant animal density. Previous studies have reported widely variable values for modern carcass density (see the supplementary material of Brassey and Sellers, 2014; and references therein), potentially due to methodological differences. Future research should also quantify intraspecific variation in extant body density, and expand the currently minimal literature on body segment densities (but see Buchner et al., 1997). CT scanning will also prove invaluable in determining pneumasticity of modern species and its impact on segment density and inertial properties.

Missing ribs and taphonomic damage.Convex hulling was developed with the intent of circumventing the subjective 'sculpting' of flesh around articulated skeletons. Although arguably successful in this respect, convex hulling has instead shifted the focus onto the reliability of skeletal articulations. 'Trunk' segments comprise the vast majority of total convex-hull volume, and resulting mass estimates are particularly sensitive to rib-cage articulation. Unfortunately, fossil ribs are frequently damaged, distorted, or missing. The thoracic ribs of Stegosaurus stenops (NHMUK R36730) were found to be straightened due to post mortem damage, resulting in a broadened, flaring ribcage and requiring further sensitivity analyses to quantify the impact of taphonomy on predicted body mass (Brassey et al., 2015). Likewise, one side of the Edinburgh dodo (NMS.Z.1993.13) ribcage required mirroring before convex hulling could be conducted to account for missing ribs (Brassey et al., 2016), and the entire torso of Sivatherium giganteum was replaced with that of a modern specimen of Giraffa prior to volumetric mass estimation (Basu et al., 2016). A consensus is currently lacking with regard to how to approach ribcage reconstructions. However, physical anthropology has a well-established practice as documented in the literature of applying morphometric analyses to constrain fossil hominid ribcage shapes (Kagaya et al., 2008; Garcia-Martinez et al., 2014; Bastir et al., 2014), and such an approach might be readily extended to other vertebrate groups when ribs are damaged or missing.
Ontogeny.-Brassey et al. (2015) found mass predictions of Stegosaurus based on limb circumference to match those of convex hulling when corrected for ontogeny via DME (see above). The implicit assumption is that predictive models based on linear metrics of the skeleton require correction for ontogeny, but convex-hull volume does not. However, it is not clear if this assumption is justified. Just as the skeleton does not scale with perfect isometry through ontogeny, it is conceivable that the $21 \%$ missing mass value originally calculated by Sellers et al. (2012) does not remain constant throughout ontogeny. Although an extreme example, the high proportion of 'baby fat' present at birth in modern humans illustrates such a shift in body composition with age (Kuzawa, 1998). It is likely that other species also experience considerable changes with age in the extent of soft tissue located beyond the bounds of the skeleton, and an ontogenetic CT series of commonly held species (e.g., Gallus) might be illuminating in this regard.

\section{FUTURE DIRECTIONS}

Recent methodological advances within virtual paleontology have been brought to bear on fossil body-mass estimation studies, and future researchers will likely continue to be early adopters of new digital techniques. Alongside exceptionally detailed fossil reconstructions, improvements in the speed and ease-of-use of CT and laser scanning are allowing for large modern comparative datasets to generated. Crucially, however, it is important to recognize that traditional allometric predictive equations will continue to be the most appropriate technique for estimating fossil body mass in the vast majority of cases. Therefore, in addition to technological advances, further progress is still to be made in terms of statistical analyses, data sharing, and the use of modern skeletal collections that will benefit all forms of fossil body-mass estimation, volumetric and otherwise.

\section{The importance of museum collections}

The nature of the fossil record available for study is largely beyond our control. Yet the quality of modern comparative data used as a basis for body-mass prediction studies can be improved. Although the osteological collections of natural history museums 
are an extremely valuable source of skeletal material, many older collections comprise wild-caught specimens collected opportunistically during exploratory trips, and later by trophy hunters (Winker, 2004). As such, important associated data (e.g., age, sex, and live body mass) are frequently absent from museum records. In the past, this has necessarily resulted in literature values being assigned to modern specimens prior to their inclusion in predictive models (e.g., Sellers et al., 2012; Brassey and Sellers, 2014). However, carcass masses have been found to deviate considerably from published literature mean values (Brassey et al., 2016, and see online peer-review history), and restricting analyses to individuals with associated body masses can severely limit sample sizes. Fortunately, some museums are still engaged in active collection of cadavers, with emphasis on those with associated data. Furthermore, whereas skins and/or skeletons are typically the end product to be archived into museum collections, many researchers would benefit from the option to perform CT scanning and soft-tissue dissections prior to specimen skeletonization. Academics and curators must continue to press for the prioritization of such collections with high research potential, and actively collaborate to maximize the scientific output of available material.

\section{Sharing lessons with ecologists}

Whereas paleontologists are necessarily restricted to indirect reconstructions of extinct species, those working on modern taxa have the presumed benefit of directly measuring variables such as body mass. Yet in reality, many modern ecological analyses seek to minimize direct contact with their study species, either due to concerns over stressing the individual, or as a means of reducing required manpower. As such, paleontologists are not unique in their desire to reconstruct body mass indirectly, and a substantial body of literature exists regarding the remote estimation of body size in modern animal species. Initial studies employed a dual parallel-laser approach as a means of measuring linear dimensions in the field (Durban and Parsons, 2006; Bergeron, 2007; Rothman et al., 2008), and 3-D photogrammetric techniques are becoming increasingly popular (Waite et al., 2007; de Bruyn et al., 2009; Postma et al., 2013). A recent interspecific analysis of modern African mammals reported reasonable success in mass prediction using a volumetric approach (Postma et al., 2015). Mass predictions were invariably overestimates, however, ranging from $11 \%$ to $49 \%$ of recorded body mass. Perhaps more of a concern, the degree of overestimation differed considerably between digestive groups (e.g., carnivores, ruminants, fermenters). Thus, despite setting out to devise a single technique applicable to multiple mammal groups, the authors acknowledge species-specific calibration still remains necessary to achieve reliable mass estimates for some modern species (Postma et al., 2015). Therefore, the assumption that broad modern calibration equations (e.g., for quadrupedal mammals, Sellers et al., 2012; for birds, Brassey and Sellers, 2014) can perform well when applied to distantly related and/or functionally dissimilar fossil taxa has been further weakened.

An additional lesson from modern ecological studies is the frequency with which body mass varies for any given individual. Body mass is known to change diurnally (Roth, 1990, and references therein; Powers, 1991), seasonally (Lindgard et al., 1995), with migration (Schaub and Jenni, 2000), with molting (Portugal et al., 2007), and with reproductive condition (Laws et al., 1975). We must recognize that short-term fluctuations in body mass are unlikely to leave their mark on the skeleton, and that any fossil body-mass estimate will therefore be unable to capture such variation (but see Kitchener, 1993, for a discussion of potential seasonality in the body mass of the dodo). Furthermore, such variability in body mass has the potential to affect our modern calibration equations when using associated body-mass data. Although this is unlikely to significantly bias the model, it could act as an additional source of noise in the predictive relationship.

\section{Invertebrates}

The existing body-mass estimation literature is overwhelmingly dominated by vertebrates, and in particular, dinosaurs. As a field, fossil body-mass estimation has its origins in dinosaur paleobiology and the reconstruction of exceptionally large terrestrial vertebrates. Comparatively few studies have considered the mass of fossil invertebrates, preferring instead to report straightforward linear metrics that are easily obtained from typically 2-D fossils. Of the rare studies requiring an estimate for fossil body mass, most are driven by biomechanical questions. 
For example, Wootton and Kukalová-Peck (2000) estimated body mass for a range of Paleozoic insects via fluid displacement of physically sculpted clay models to investigate wing-loading allometry. Likewise, segmental body-mass properties have been calculated for Paleozoic ammonoids to test hypotheses for the function of the phragmocone (Naglik et al., 2015). As a growing number of micro-CT and synchrotron-CT studies demonstrate exceptional 3-D preservation of fossil invertebrates (Garwood et al., 2009; Garwood and Dunlop, 2014), volumetric reconstructions and resulting body-mass sets are increasingly obtainable, opening up the potential for further biomechanical analyses.

\section{Communicating uncertainty}

Fossil body-mass estimates receive considerable attention in terms of popular media coverage, presumably due to public interest in 'giants' and 'dwarfs', and perhaps in part because mass estimation can be a straightforward topic for nonspecialists to grasp. Yet published body-mass predictions are often accompanied by extremely large error bars, and uncertainties that must be acknowledged and carried forward into further analyses. Although it is unrealistic to expect all media coverage to report confidence intervals around mass estimates, or the nuances of any one particular technique, there is a responsibility to try to convey uncertainty alongside reports of our research. In this sense, fossil bodymass estimation is particularly amenable because volumetric models are visually intuitive, and the sensitivity of resulting body-mass predictions to particular variables can be explored graphically.

\section{CONCLUSIONS}

All three categories of body-fossil mass estimation discussed here (allometric predictive equations, volumetric reconstructions, and hybrid techniques) have benefitted from recent advances in 3-D imaging technology, including faster and high-resolution $\mathrm{CT}$, surface laser scanning, photogrammetry, and increasingly user-friendly and/or open-source software. And whereas the current interest in bodymass estimation is encouraging, it does also warrant caution. In particular, it is important to not become distracted by the desire to find one 'true' body-mass value for a given fossil specimen. Most likely, all

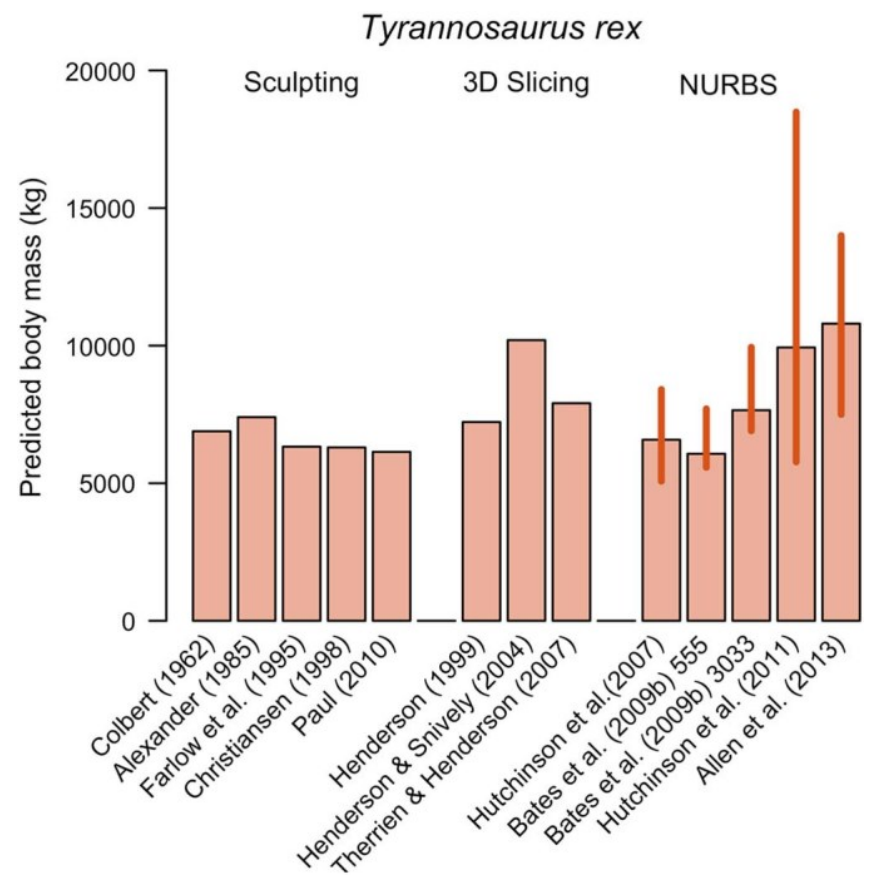

FIGURE 8.-Predicted body mass for adult Tyrannosaurus rex, calculated using various volumetric approaches. Reported value from Hutchinson et al. (2007) is a best-guess estimate; that from Hutchinson et al. (2011) is mean body-mass value for four adult specimens. Values from Bates et al. (2009) refer to two T. rex specimens, from the Museum of the Rockies (MOR 555) and the Black Hills Institute (BHI 3033), respectively. Error bars on NURBS values represent maximum and minimum results of sensitivity analyses, and were not necessarily deemed physiologically plausible by those authors. 
body-mass estimates are wrong to some extent. Yet interest lies in the degree to which results differ when applying alternative methods, and the underlying cause for such disagreements. Sensitivity analyses are now commonplace, and it is increasingly expected to report uncertainty alongside fossil reconstructions. Figure 8 highlights the results of 11 volumetric body mass estimates for Tyrannosaurus rex published over the course of 50 years. What is particularly striking is not necessarily any shift in mean body-mass estimates, but rather the trend toward reporting sensitivity analyses. Essentially, rather than decreasing uncertainty in fossil body-mass estimation, the application of virtual paleontology has made it easier to quantify and explicitly acknowledge the potential sources of error that have been present in our models all along.

\section{ACKNOWLEDGMENTS}

This paper is dedicated to the late R. McNeill Alexander, whose early work anticipated and inspired many of the 'virtual' methods outlined here and who, throughout his career, significantly influenced the study of fossil body mass.

Firstly, I thank I. Rahman and L. Tapanila for the invitation to contribute to this volume. I would also like to acknowledge W.I. Sellers (University of Manchester) and K.T. Bates (University of Liverpool) for useful discussion and development of the convexhulling technique. J.D. Gardiner (University of Salford) provided helpful comments on an early version of the manuscript and assisted with figure preparation. The author is funded by a BBSRC Future Leader Fellowship (BB/N010957/1). Additional support was provided by the Jurassic Foundation.

\section{REFERENCES}

Aiello, L.C., and Wood, B.A., 1994, Cranial variables as predictors of hominine body mass: American Journal of Physical Anthropology, v. 95, p. 409-426.

Alexander, R.M.N., 1983a, Allometry of the leg bones of moas (Dinornithes) and other birds: Journal of Zoology, v. 200, p. 215-231.

Alexander, R.M.N., 1983b, Animal Mechanics: Oxford, UK, Blackwell Scientific, $301 \mathrm{p}$.

Alexander, R.M.N., 1983c, On the massive legs of a moa (Pachyornis elephantopus, Dinornithes): Journal of Zoology, v. 201, p. 363-376.
Alexander, R.M.N., 1985, Mechanics of posture and gait of some large dinosaurs: Zoological Journal of the Linnean Society, v. 83, p. 1-25.

Allen, V., Bates, K.T., Li, Z., and Hutchinson, J.R., 2013, Linking the evolution of body shape and locomotor biomechanics in bird-line archosaurs: Nature, v. 497, p. 104-107.

Anderson, J.F., Hall-Martin, A., and Russell, D.A., 1985, Long-bone circumference and weight in mammals, birds and dinosaurs: Journal of Zoology, v. 207, p. 53-61.

Attard, M.R.G., Wilson, L.A.B., Worthy, T.H., Scofield, P., Johnston, P., Parr, W.C.H., and Wroe, S., 2016, Moa diet fits the bill: Virtual reconstruction incorporating mummified remains and prediction of biomechanical performance in avian giants: Proceedings of the Royal Society of London B, Biological Sciences, v. 283, art. 20152043, DOI: 10.1098/rspb.2015.2043.

Auat Cheein, F.A., and Guivant, J., 2014, SLAM-based incremental convex hull processing approach for treetop volume estimation: Computers and Electronics in Agriculture, v. 102, p. 19-30.

Barber, C.B., Dobkin, D.P., and Huhdanpaa, H.T., 1996, The quickhull algorithm for convex hulls: ACM Transactions on Mathematical Software, v. 22, p. 469-483.

Barber, C.B., Habel, K., Grasman, R., Gramacy, R., Stahel, A., and Sterratt, D., 2015, Geometry: Mesh generation and surface tesselation: https://cran.r-project. org/web/packages/geometry/index.html (accessed July 2016).

Bastir, M., Higuero, A., Ríos, L., and Martínez, D.G., 2014, Three-dimensional analysis of sexual dimorphism in human thoracic vertebrae: Implications for the respiratory system and spine morphology: American Journal of Physical Anthropology, v. 155, p. 513-521.

Basu, C., Falkingham, P.L., and Hutchinson, J.R., 2016, The extinct, giant giraffid Sivatherium giganteum: Skeletal reconstruction and body mass estimation: Biology Letters, v. 12, art. 20150940, DOI: 10.1098/ rsbl.2015.0940.

Bates, K.T., Falkingham, P.L., Breithaupt, B.H., Hodgetts, D., Sellers, W.I., and Manning, P.L., 2009a, How big was 'Big Al'? Quantifying the effect of soft tissue and osteological unknowns on mass predictions for Allosaurus (Dinosauria: Theropoda): Palaeontologia Electronica, v. 12, no. 3, art. 14A, p. 1-33A. http:// palaeo-electronica.org/2009_3/186/index.html.

Bates, K.T., Falkingham, P.L., Macaulay, S., Brassey, C., and Maidment, S.C.R., 2015, Downsizing a giant: Re-evaluating Dreadnoughtus body mass: Biology Letters, v. 11, art. 20150215, DOI: 10.1098/ rsbl.2015.0215.

Bates, K.T., Manning, P.L., Hodgetts, D., and Sellers, W. I., 2009b, Estimating mass properties of dinosaurs 
using laser imaging and 3D computer modeling: PLoS ONE, v. 4, art. e4532, DOI: 10.1371/journal. pone.0004532.

Bates, K.T., Manning, P.L., Margetts, L., and Sellers, W.I., 2010, Sensitivity analysis in evolutionary robotic simulations of bipedal dinosaur running: Journal of Vertebrate Paleontology, v. 30, p. 458-466.

Benson, R.B.J., Campione, N.E., Carrano, M.T., Mannion, P.D., Sullivan, C., Upchurch, P., and Evans, D.C., 2014, Rates of dinosaur body mass evolution indicate 170 million years of sustained ecological innovation on the avian stem lineage: PLoS Biology, v. 12, art. e1001853, DOI: 10.1371/journal.pbio.1001853.

Bergeron, P., 2007, Parallel lasers for remote measurements of morphological traits: Journal of Wildlife Management, v. 71, p. 289-292.

Blumenbach, J.F., 1799, Handbuch der Naturgeschichte, 6th ed., Göttingen, Germany, Dieterich, 668 p.

Braddy, S.J., Poschmann, M., and Tetlie, O.E., 2008, Giant claw reveals the largest ever arthropod: Biology Letters, v. 4, p. 106-109.

Bramwell, C.D., and Whitfield, G.R., 1974, Biomechanics of Pteranodon: Philosophical Transactions of the Royal Society B, Biological Sciences, v. 267, p. 503-581. Brassey, C.A., and Gardiner, J., 2015, An advanced shapefitting algorithm applied to quadrupedal mammals: Improving volumetric mass estimates: Royal Society Open Science, v. 2, art. 50302, DOI: 10.1098/ rsos. 150302.

Brassey, C.A., Holdaway, R.N., Packham, A.G., Anné, J., Manning, P.L., and Sellers, W.I., 2013, More than one way of being a moa: Differences in leg bone robustness map divergent evolutionary trajectories in Dinornithidae and Emeidae (Dinornithiformes): PLoS ONE, v. 8, art. e82668, DOI: 10.1371/journal.pone.0082668.

Brassey, C.A., Maidment, S.C.R., and Barrett, P.M., 2015, Body mass estimates of an exceptionally complete Stegosaurus (Ornithischia: Thyreophora): Comparing volumetric and linear bivariate mass estimation methods: Biology Letters, v. 11, art. 20140984, DOI: 10.1098/rsbl.2014.0984.

Brassey, C.A., O’Mahoney, T.G., Kitchener, A.C., Manning, P.L., and Sellers, W.I., 2016, Convex-hull mass estimates of the dodo (Raphus cucullatus): Application of a CT-based mass estimation technique: PeerJ, v. 4, art. e1432, DOI: 10.7717/peerj.1432.

Brassey, C.A., and Sellers, W.I., 2014, Scaling of convex hull volume to body mass in modern primates, non-primate mammals and birds: PLoS ONE, v. 9, art. e91691, DOI: 10.1371/journal.pone.0091691.

Brower, B.C., and Veinus, J., 1981, Allometry in pterosaurs: The University of Kansas Paleontology Contributions, v. 105, p. 1-32.
Buchner, H.H.F., Savelberg, H.H.C.M., Schamhardtt, H. C., and Barneveld, A., 1997, Inertial properties of Dutch Warmblood horses: Journal of Biomechanics, v. 30, p. 653-658.

Campione, N.E., and Evans, D.C., 2012, A universal scaling relationship between body mass and proximal limb bone dimensions in quadrupedal terrestrial tetrapods: BMC Biology, v. 10, art. 60, DOI: 10.1186/1741-7007-10-60.

Christiansen, P., 1997, Locomotion in sauropod dinosaurs: Gaia, v. 14, p. 45-75.

Christiansen, P., 1998, Strength indicator values of theropod long bones, with comments on limb proportions and cursorial potential: Gaia, v. 15, p. 241-255.

Christiansen, P., and Bonde, N., 2002, Limb proportions and avian terrestrial locomotion: Journal of Ornithology, v. 143, p. 356-371.

Christiansen, P., and Paul, G., 2001, Limb bone scaling, limb proportions, and bone strength in neoceratopsian dinosaurs: Gaia, v. 16, p. 13-29.

Cignoni, P., Corsini, M., and Ranzuglia, G., 2008, Meshlab: An open-source 3D mesh processing system: Ercim News, v. 73, p. 45-46.

Colbert, E., 1962, The weights of dinosaurs: American Museum Novitates, v. 2075, p. 1-16.

Cuvier, G., 1796, Notice sur le squelette d'une très-grande espèce de quadrupède inconnue jusqu'à présent, trouvé au Paraquay, et déposé au cabinet d'histoire naturelle de Madrid: Magasin Encyclopèdique: ou Journal des Sciences, des Lettres et des Arts, v. 1, p. 303-310. v. 2, p. 227-228.

Damuth, J., and MacFadden, B.J., 1990, Body Size in Mammalian Paleobiology: Estimation and Biological Implications: Cambridge, UK, Cambridge University Press, $412 \mathrm{p}$.

de Bruyn, P.J.N., Bester, M.N., Carlini, A.J., and Oosthuizen, C.W., 2009, How to weigh an elephant seal with one finger: A simple three-dimensional photogrammetric application: Aquatic Biology, v. 5, p. 31-39.

Dickison, M., 2007, The Allometry of Giant Flightless Birds [PhD Thesis]: Durham, North Carolina, Duke University, $89 \mathrm{p}$.

Dunning, J., 2007, CRC Handbook of Avian Body Masses: Boca Raton, Florida, CRC Press, 672 p.

Durban, J.W., and Parsons, K.M., 2006, Laser-metrics of free-ranging killer whales: Marine Mammal Science, v. 22, p. 735-743.

Erickson, G.M., and Tumanova, T.A., 2000, Growth curve of Psittacosaurus mongoliensis Osborn (Geratopsia: Psittacosauridae) inferred from long bone histology: Zoological Journal of the Linnean Society, v. 130 , p. $551-566$.

Falconer, H., and Cautley, P.T., 1836, Sivatherium giganteum, a new fossil ruminant genus, from the 
valley of the Markanda, in the Sivalik branch of the sub-Himalayan Mountains: Journal of the Asiatic Society of Bengal, v. 5, p. 38-50.

Fariña, R.A., Vizcaíno, S.F., and Bargo, M.S., 1998, Body mass estimations in Lujanian (late Pleistocene-early Holocene of South America) mammal megafauna: Matozoologia Neotropical, v. 5, p. 87-108.

Fariña, R.A, Vizcaíno, S.F., and De Iuliis, G., 2013, Megafauna: Giant Beasts of Pleistocene South America: Bloomington, Indiana, Indiana University Press, 448 p.

Farlow, J.O., Smith, M.B., and Robinson, J.M., 1995, Body mass, bone 'strength indicator' and cursorial potential of Tyrannosaurus rex: Journal of Vertebrate Paleontology, v. 15, p. 713-725.

Field, D.J., Lynner, C., Brown, C., and Darroch, S.A.F, 2013, Skeletal correlates for body mass estimation in modern and fossil flying birds: PLoS ONE, v. 8, art. e82000, DOI: 10.1371/journal.pone.0082000.

Garcia-Martinez, D., Barash, A., Recheis, W., Utrilla, C., Torres Sinchez, I., Garcia Rio, F., and Bastir, M., 2014, On the chest size of Kebara 2: Journal of Human Evolution, v. 70, p. 69-72.

Garwood, R.J., and Dunlop, J.A., 2014, Threedimensional reconstruction and the phylogeny of extinct chelicerate orders: PeerJ, v. 2, art. e641, DOI: 10.7717/peerj.641.

Garwood, R.J., Dunlop, J.A., and Sutton, M.D., 2009, High-fidelity X-ray micro-tomography reconstruction of siderite-hosted Carboniferous arachnids: Biology Letters, v. 5, p. 841-844.

Gregory, W.K., 1905, The weight of the Brontosaurus: Science, v. 22, p. 572.

Gunga, H.-C., Kirsch, K.A., Baartz, F., Rocker, L., Heinrich, W.-D., Lisowski, W., Wiedemann, A., and Albertz, J., 1995, New data on the dimensions of Brachiosaurus brancai and their physiological implications: Naturwissenschaften, v. 82, p. 190-192.

Gunga, H.-C., Kirsch, K., Rittweger, J., Rocker, L., Clarke, A., Albertz, J., Wiedemann, A., Mokry, S., Suthau, T., Wehr, A., Heinrich, W.-D., and Schultze, H.-P., 1999, Body size and body volume distribution in two sauropods from the Upper Jurassic of Tendaguru/ Tansania (East Africa): Mitteilungen aus dem Museum für Naturkunde in Berlin, Geowissenschaftliche Reihe, v. 2, p. 91-102.

Gunga, H.-C., Suthau, T., Bellmann, A., Friedrich, A., Schwanebeck, T., Stoinski, S., Trippel, T., Kirsch, K., and Hellwich, O., 2007, Body mass estimations for Plateosaurus engelhardti using laser scanning and 3D reconstruction methods: Naturwissenschaften, v. 94, p. 623-630.

Gunga, H.-C., Suthau, T., Bellmann, A., Stoinski, S., Friedrich, A., Trippel, T., Kirsch, K., and Hellwich, O.,
2008, A new body mass estimation of Brachiosaurus brancai Janensch, 1914 mounted and exhibited at the Museum of Natural History (Berlin, Germany): Fossil Record, v. 11, p. 33-38.

Haynes, G., 1991, Mammoths, Mastodonts, and Elephants: Cambridge, UK, Cambridge University Press, 428 p.

Hazlehurst, G.A., 1991, The Morphometric and Flight Characteristics of the Pterosauria: Bristol, UK, University of Bristol, $274 \mathrm{p}$.

Hazlehurst, G.A., and Rayner, J.M., 1992, Flight characteristics of Triassic and Jurassic Pterosauria: An appraisal based on wing shape: Paleobiology, v. 18, p. 447-463.

Henderson, D.M., 1999, Estimating the masses and centers of mass of extinct animals by 3-D mathematical slicing: Paleobiology, v. 25, p. 88-106.

Henderson, D.M., 2004, Tipsy punters: Sauropod dinosaur pneumaticity, buoyancy, and aquatic habits: Biology Letters, v. 271, p. 180-183.

Henderson, D.M., 2006, Burly gaits: Centers of mass, stability, and the trackways of sauropod dinosaurs: Journal of Vertebrate Paleontology, v. 26, p. 907-921.

Henderson, D.M., 2010, Pterosaur body mass estimates from three-dimensional mathematical slicing: Journal of Vertebrate Paleontology, v. 30, p. 768-785.

Henderson, D.M., and Snively, E., 2004, Tyrannosaurus en pointe: Allometry minimized the rotational inertia of large carnivorous dinosaurs: Biology Letters, v. 271, p. $57-60$.

Heptonstall, W.B., 1971, An analysis of the flight of the Cretaceous pterodactyl Pteranodon ingens (March): Scottish Journal of Geology, v. 7, p. 61-78.

Holland, W.J., 1915, A new species of Apatosaurus: Annals of the Carnegie Museum, v. 10, p. 143-145.

Hone, D.W.E., and Henderson, D.M., 2014, The posture of floating pterosaurs: Ecological implications for inhabiting marine and freshwater habitats: Palaeogeography, Palaeoclimatology, Palaeoecology, v. 394, p. 89-98.

Hurlburt, G., 1999, Comparison of body mass estimation techniques, using Recent reptiles and the pelycosaur Edaphosaurus boanerges: Journal of Vertebrate Paleontology, v. 19, p. 338-350.

Hutchinson, J.R., Bates, K.T., Molnar, J., Allen, V., and Makovicky, P.J., 2011, A computational analysis of limb and body dimensions in Tyrannosaurus rex with implications for locomotion, ontogeny, and growth: PLoS ONE, v. 6, art. e26037, DOI: 10.1371/journal. pone. 0026037 .

Hutchinson, J.R., Ng-Thow-Hing, V., and Anderson, F.C., 2007, A 3D interactive method for estimating body segmental parameters in animals: Application to the turning and running performance of Tyrannosaurus rex: Journal of Theoretical Biology, v. 246, p. 660-680. 
Janensch, W., 1914, Übersicht über der Wirbeltierfauna der Tendaguru-Schichten nebst einer kurzen Charakterisierung der neu aufgefuhrten Arten von Sauropoden: Archiv fur Biontologie, v. 3, p. 81-110.

Jiménez, P., Thomas, F., and Torras, C., 2001, 3D collision detection: A survey: Computers \& Graphics, v. 25 , p. 269-285.

Jones, T.D., Farlow, J.O., Ruben, J.A., Henderson, D.M., and Hillenius, W.J., 2000, Cursoriality in bipedal archosaurs: Nature, v. 406, p. 716-718.

Kagaya, M., Ogihara, N., and Nakatsukasa, M., 2008, Morphological study of the anthropoid thoracic cage: Scaling of thoracic width and an analysis of rib curvature: Primates, v. 49, p. 89-99.

Kaiser, A., and Klok, J., 2008, Do giant claws mean giant bodies? An alternative view on exaggerated scaling relationships: Biology letters, v. 4, p. 279-280.

Kaufman, J., and Smith, R., 2002, Statistical issues in the prediction of body mass for Pleistocene canids: Lethaia, v. 35, p. 32-334.

Kitchener, A.C., 1993, The external appearance of the dodo, Raphus cucullatus: Archives of Natural History, v. 20, p. 279-301.

Kuzawa, C.W., 1998, Adipose tissue in human infancy and childhood: An evolutionary perspective: Yearbook of Physical Anthropology, v. 41, p. 177-209.

Lacovara, K.J., Lamanna, M.C., Ibiricu, L.M., Poole, J.C., Schroeter, E.R., Ullmann, P.V., Voegele, K.K., Boles, Z.M., Carter, A.M., Fowler, E.K., Egerton, V.M., Moyer, A.E., Coughenour, C.L., Schein, J.P., Harris, J.D., Martínez, R.D., and Novas, F.E., 2014, A gigantic, exceptionally complete titanosaurian sauropod dinosaur from southern Patagonia, Argentina: Scientific Reports, v. 4, art. 6196, DOI: 10.1038/srep06196.

Laws, R.M., Parker, I.S.C., and Johnstone, R.C.B., 1975, Elephants and Their Habitats: Oxford, UK, Clarendon Press, $376 \mathrm{p}$.

Lawson, D.A., 1975, Could pterosaurs fly?: Science, v. 188 , p. 676-678.

Lindgard, K., Stokkan, K.A., and Naslund, S., 1995, Annual changes in body mass in captive Svalbard ptarmigan: Role of changes in locomotor activity and food intake: Journal of Comparative Physiology B, v. 165 , p. $445-449$.

Linnaeus, C., 1758, Systema Naturae per Regna tria Naturae, secundum Classes, Ordines, Genera, Species, cum Characteribus, Differentis, Synonymis, Locis, 10th ed.: Stockholm, Sweden, Laurentii, Slavi, 824 p.

Maidment, S.C.R., Henderson, D.M., and Barrett, P.M., 2014, What drove reversions to quadrupedality in ornithischian dinosaurs? Testing hypotheses using centre of mass modeling: Naturwissenschaften, v. 101, p. 989-1001.
Mallison, H., 2010, The digital Plateosaurus I: Body mass, mass distribution and posture assessed using CAD and CAE on a digitally mounted complete skeleton: Palaeontologia Electronica, v. 13, art. 8A, http://palaeo-electronica.org/2010_2/198/ index.html.

Marsh, O.C., 1877, Notice of new dinosaurian reptiles from the Jurassic Formation: American Journal of Science, v. 3, p. 513-514.

Marsh, O.C., 1879, Notice of new Jurassic reptiles: American Journal of Science, v. 108, p. 501-505.

Marsh, O.C., 1887, Principal characters of American Jurassic dinosaurs, part IX, The skull and dermal armor of Stegosaurus: American Journal of Science, series 3, v. 34, p. 413-417.

Martin-Silverstone, E., Vincze, O., McCann, R., Jonsson, C.H.W., Palmer, C., Kaiser, G., and Dyke, G., 2015, Exploring the relationship between skeletal mass and total body mass in birds: PLoS ONE, v. 10, art. e0141794, DOI: 10.1371/journal.pone.0141794.

Mazzetta, G., Christiansen, P., and Farina, R., 2004, Giants and bizarres: Body size of some southern South American Cretaceous dinosaurs: Historical Biology, v. 16, p. 1-13, DOI: 10.1080/0891296041000 1715132.

McKinney, M.L., 1997, Extinction vulnerability and selectivity: Combining ecological and paleontological views: Annual Review of Ecology and Systematics, v. 28, p. 495-516.

Millien, V., and Bovy, H., 2010, When teeth and bones disagree: Body mass estimation of a giant extinct rodent: Journal of Mammalogy, v. 91, p. 11-18.

Moncunill-Solé, B., Jordana, X., Marín-Moratalla, N., Moyà-Solà, S., and Köhler, M., 2014, How large are the extinct giant insular rodents? New body mass estimations from teeth and bones: Integrative Zoology, v. 9, p. 197-212.

Mones, A., 1980, Un Neoepiblemidae del Plioceno Medio (Formacion Urumaco) de Venezuela (Mammalia: Rodentia: Caviomorpha): Ameghiniana, v. 17, p. $277-279$.

Montani, R., 2001, Estimating body mass from silhouettes: Testing the assumption of elliptical body crosssections: Paleobiology, v. 27, p. 735-750.

Naglik, C., Rikhtegar, F., and Klug, C., 2015, Buoyancy of some Palaeozoic ammonoids and their hydrostatic properties based on empirical 3D-models: Lethaia, v. 49 , p. 3-12.

Olson, V.A., and Turvey, S.T., 2013, The evolution of sexual dimorphism in New Zealand giant moa (Dinornis) and other ratites: Proceedings of the Royal Society B, Biological Sciences, v. 280, art. 20130401, DOI: 10.1098/rspb.2013.0401. 
Osborn, H.E., 1905, Tyrannosaurus and other Cretaceous carnivorous dinosaurs: Bulletin of the American Museum of Natural History, v. 21, p. 259-265.

Owen, R., 1846, Proceedings of a meeting: Owen read his second memoir on Dinornis remains: Proceedings of the Zoological Society London, v. 14, no. 160, p. 46-49.

Owen, R., 1856, On Dinornis Part VII: Containing a description of the bones of the leg and foot of the Dinornis elephantopus: Proceedings of the Zoological Society of London, v. 1856, p. 54-61.

Packard, G.C., Boardman, T.J., and Birchard, G.F., 2009, Allometric equations for predicting body mass of dinosaurs: Journal of Zoology, v. 279, p. 102-110.

Pagel, M., 1991, Constructing 'everyanimal': Nature, v. 351, p. $532-533$.

Paul, G., 1997, Dinosaur models: The good, the bad, and using them to estimate the mass of dinosaurs, in Wolberg, D.L., Stump, E., and Rosenberg, E., eds., Dinofest International: Proceedings of a Symposium held at Arizona State University: Philadelphia, Pennsylvania, Academy of Natural Sciences, p. 129-142.

Paul, G., 2010, The Princeton Field Guide to Dinosaurs: Princeton, New Jersey, Princeton University Press, 320 p.

Portugal, S.J., Green, J.A., and Butler, P.J., 2007, Annual changes in body mass and resting metabolism in captive barnacle geese (Branta leucopsis): The importance of wing moult: The Journal of Experimental Biology, v. 210, p. 1391-1397.

Postma, M., Bester, M.N., and de Bruyn, P.J.N., 2013, Spatial variation in female southern elephant seal mass change assessed by an accurate non-invasive photogrammetry method: Antarctic Science, v. 25, p. 731-740.

Postma, M., Tordiffe, A.S.W., Hofmeyr, M.S., Reisinger, R.R., Bester, L.C., Buss, P.E., and de Bruyn, P.J.N., 2015, Terrestrial mammal three-dimensional photogrammetry: Multispecies mass estimation: Ecosphere, v. 6, p. 1-16.

Powers, D.R., 1991, Diurnal variation in mass, metabolic rate, and respiratory quotient in Anna's and Costa's hummingbirds: Physiological Zoology, v. 64, p. 850-870.

Prange, H.D., Anderson, J.F., and Rahn, H., 1979, Scaling of skeletal mass to body mass in birds and mammals: American Naturalist, v. 113, p. 103-122.

Roth, V.L., 1990, Insular dwarf elephants: A case study in body mass estimation and ecological inference, in Damuth, J., and MacFadden, B., eds., Body Size in Mammalian Paleobiology: Estimates and Biological Implications: Cambridge, UK, Cambridge University Press, p. 151-180.
Rothman, J.M., Chapman, C.A., Twinomugisha, D., Wasserman, M.D., Lambert, J.E., and Goldberg, T.L., 2008, Measuring physical traits of primates remotely: The use of parallel lasers: American Journal of Primatology, v. 70, p. 1-5.

Ruff, C.B., Scott, W.W., and Liu, A.Y., 1991, Articular and diaphyseal remodeling of the proximal femur with changes in body mass in adults: American Journal of Physical Anthropology, v. 86, p. 397-413.

Sanchez-Villagra, M.R., Aguilera, O., and Horovitz, I., 2003, The anatomy of the world's largest extinct rodent: Science, v. 301, p. 1708-1710.

Schaub, M., and Jenni, L., 2000, Body mass of six long-distance migrant passerine species along the autumn migration route: Journal für Ornithologie, v. 141, p. $441-460$.

Schmidt-Nielsen, K., 1984, Scaling: Why is Animal Size So Important?: Cambridge, UK, Cambridge University Press, $241 \mathrm{p}$.

Schulman, J., Duan, Y., Ho, J., Lee, A., Awwal, I., Bradlow, H., Pan, J., Patil, S., Goldberg, K., and Abbeel, P., 2014, Motion planning with sequential convex optimization and convex collision checking: The International Journal of Robotics Research, v. 33, p. 1251-1270.

Scull, P., Palmer, M., Frey, F., and Kraly, E., 2012, A comparison of two home range modeling methods using Ugandan mountain gorilla data: International Journal of Geographical Information Science, v. 26, p. 2111-2121.

Seebacher, F., 2001, A new method to calculate allometric length-mass relationships of dinosaurs: Journal of Vertebrate Paleontology, v. 21, p. 51-60.

Sellers, W.I., Hepworth-Bell, J., Falkingham, P.L., Bates, K.T., Brassey, C.A., Egerton, V.M., and Manning, P.L., 2012, Minimum convex hull mass estimations of complete mounted skeletons: Biology Letters, v. 8, p. 842-845.

Sellers, W.I., and Manning, P.L., 2007, Estimating dinosaur maximum running speeds using evolutionary robotics: Proceedings of the Royal Society B, Biological Sciences, v. 274, p. 2711-2716.

Sellers, W.I., Margetts, L., Coria, R.A., and Manning, P.L., 2013, March of the titans: The locomotor capabilities of sauropod dinosaurs: PLoS ONE, v. 8, art. e78733, DOI: 10.1371/journal.pone.0078733.

Silva, M., and Downing, J.A., 1995, CRC Handbook of Mammalian Body Masses: Boca Raton, Florida, CRC Press, 359 p.

Smith, R.J., 1993, Logarithmic transformation bias in allometry: American Journal of Physical Anthropology, v. 90, p. 215-228. 
Smith, R.J., 2002, Estimation of body mass in paleontology: Journal of Human Evolution, v. 43, p. 271-287.

Smith, R.J., 2009, Use and misuse of the reduced major axis for line-fitting: American Journal of Physical Anthropology, v. 140, p. 476-486.

Snively, E., Cotton, J.R., Ridgely, R., and Witmer, L.M., 2013, Multibody dynamics model of head and neck function in Allosaurus (Dinosauria, Theropoda): Palaeontologia Electronica, v. 16, no. 2, art. 11A, http://palaeoelectronica.org/content/2013/389-allosaurus-feeding.

Spocter, M.A., and Manger, P.R., 2007, The use of cranial variables for the estimation of body mass in fossil hominins: American Journal of Physical Anthropology, v. 134, p. 92-105.

Stoinski, S., Suthau, T., and Gunga, H.-C., 2011, Reconstructing body volume and surface area of dinosaurs using laser scanning and photogrammetry, in Klein, N., Remes, K., Gee, C.T., and Sander, P.M., eds., Biology of Sauropod Dinosaurs: Understanding the Life of Giants: Bloomington, Indiana, Indiana University Press, p. 94-104.

Sutton, M.D., Rahman, I.A., and Garwood, R.J., 2014, Techniques for Virtual Palaeontology: Chichester, UK, John Wiley \& Sons, 200 p.

Therrien, F., and Henderson, D.M., 2007, My theropod is bigger than yours...or not: Estimating body size from skull length in theropods: Journal of Vertebrate Paleontology, v. 27, p. 108-115.

Tschopp, E., Mateus, O., and Benson, R.B.J., 2015, A specimen-level phylogenetic analysis and taxonomic revision of Diplodocidae (Dinosauria, Sauropoda): PeerJ, v. 3, art. e857, DOI: 10.7717/ peerj. 857.

von Meyer, H., 1837, Briefliche Mitteilung an Prof. Bronn über Plateosaurus engelhardti: Neues Jahrbuch für
Mineralogie, Geognosie, Geologie und PetrefaktenKunde, v. 1837, p. 316.

Waite, J.N., Schrader, W.J., Mellish, J.E., and Horning, M., 2007, Three-dimensional photogrammetry as a tool for estimating morphometrics and body mass of Steller sea lions: Canadian Journal of Fisheries and Aquatic Sciences, v. 64, p. 296-303.

Wiedemann, A., Suthau, T., and Albertz, J., 1999, Photogrammetric survey of dinosaur skeletons: Fossil Record, v. 2, p. 113-119.

Winker, K., 2004, Natural history museums in a postbiodiversity era: Bioscience, v. 54, p. 455-459.

Witton, M., and Habib, M., 2010, On the size and flight diversity of giant pterosaurs, the use of birds as pterosaur analogues and comments on pterosaur flightlessness: PLoS ONE, v. 5, art. e13982, DOI: 10.1371/ journal.pone.0013982.

Witton, M.P., 2008, A new approach to determining pterosaur body mass and its implications for pterosaur flight: Zitteliana, v. B28, p. 143-158.

Wootton, R. J., and Kukalová-Peck, J., 2000, Flight adaptations in Palaeozoic Palaeoptera (Insecta): Biological Reviews, v. 75, p. 129-167.

Worthy, T., and Scofield, R., 2012, Twenty-first century advances in knowledge of the biology of moa (Aves: Dinornithiformes): a new morphological analysis and moa diagnoses revised: New Zealand Journal of Zoology, v. 39, p. 87-153.

Wroe, S., Crowther, M., Dortch, J., and Chong, J., 2004, The size of the largest marsupial and why it matters: Biology Letters, v. 271, p. S34-S36.

Wroe, S., Myers, T., Seebacher, F., Kear, B., Gillespie, A., Crowther, M., and Salisbury, S., 2003, An alternative method for predicting body mass: The case of the Pleistocene marsupial lion: Paleobiology, v. 29, p. $403-411$. 